\title{
Retrofit of existing steel structures against progressive collapse through roof-truss
}

\author{
Fabio Freddi ${ }^{1, *}$, Luca Ciman ${ }^{2}$ and Nicola Tondini ${ }^{3}$ \\ ${ }^{1}$ Lecturer, Dept. of Civil, Env. \& Geomatic Eng., Univ. College of London, London WC1E 6BT, U.K. \\ *Corresponding Author. Tel.: +44 (0)7752360204. E-mail address: f.freddi@ucl.ac.uk \\ ${ }^{2}$ MSc Student, Dept. of Civil, Env. and Mech. Eng., Univ. of Trento, via Mesiano 77, 38123, Trento, Italy \\ E-mail address: luca.ciman@alumni.unitn.it \\ ${ }^{3}$ Assistant Professor, Dept. of Civil, Env. and Mech. Eng., Univ. of Trento, via Mesiano 77, 38123, Trento, Italy \\ E-mail address: nicola.tondini@ unitn.it
}

\section{ABSTRACT}

10 The paper presents the results of a comprehensive study on the evaluation of the effectiveness of a retrofit strategy of existing steel buildings against progressive collapse. In this respect, it investigates the performance and the design of a retrofit solution to increase the robustness of steel Moment Resisting Frame buildings. A truss steel system added at the building's rooftop level (i.e., 'roof-truss'), and intended to define an alternative load path, was investigated as a retrofit solution. The numerical model key components, including the plastic hinges and the beam-column connections, were validated against available experimental results. The validated models were then used to study the robustness of the structure under column loss scenarios by means of non-linear static and dynamic analyses performed in OpenSees. The simulations allowed for the identification of possible failure modes and alternative load paths together with the definition of the Dynamic Increase Factor $(D I F)$. In this regard, it is shown that column buckling is critical for the selected case study. Moreover, the outcomes showed how the proposed retrofit solution allows the definition of effective alternative load paths when subjected to column loss scenarios and informs on the critical details that should be checked by employing this retrofit system.

Keywords: Progressive collapse; Steel moment resisting frames; Retrofit; Roof-truss; Dynamic Increase Factor; Nonlinear static analysis; Non-linear dynamic analysis.

\section{INTRODUCTION}

Extreme events (i.e., terrorist attacks, vehicle impacts, explosions, etc.) often cause local damage to building structures and pose a serious threat when one or more vertical load-bearing components fail, leading to the progressive collapse of the entire structure or a large part of it. Since the beginning of the $21^{\text {st }}$ century, there has been growing interest in occurrence, the consequences can be very high. Thus, the focus is now on achieving 'robust' and 'resilient' buildings that can remain operational after such an event. This is paramount when they form part of critical infrastructures and/or they are occupied by a large number of people or are open to the public.

Fundamental characteristics such as stiffness, strength, ductility, and stability of a structure are conventionally 
controlled through codified design procedures with the aim to meet specific requirements with respect to code defined design loads. However, during their life span, structures could be exposed to accidental events, which are outside the coverage of normal design processes. These events are unpredictable in terms of cause, probability of occurrence and intensity and hence is not feasible, nor practical or economical to include their effects within a conventional design procedure. A more rational and well-recognized approach is to provide the structure with the ability to withstand such events without being damaged to an extent disproportionate to the original cause [1]. Safety against disproportionate collapse is usually based on the residual strength and/or the Alternate load Path Method (APM) [6], where the knowledge of load transfer mechanisms from the damaged to the undamaged part of the structure is one of the key aspects of the design.

Several disasters of different origins led to growing interest in the response of structures subjected to extreme loads such as impact or blast. Among others, cases with high relevance are the collapse of the Ronan Point Building (London, 1968) [7], of the Murrah Federal Building (Oklahoma City, 1995) [8] and the World Trade Center (New York, 2001) [9]. Since the 1940s, many research studies focused on this issue, investigating widely diverse aspects of the problem by performing components $[$ e.g., 10, 11, 12,13] and large scale experimental tests $[$ e.g., 14, 15, 16, 17, $18,19,20,21,22]$, numerical modelling and simulations [e.g., 23, 24, 25, 26, 27, 28, 29, 30, 31] and investigating several aspects of the design against progressive collapse [e.g., 32, 33]. These studies allowed building up an increasingly understanding of the structural response in these scenarios and the definition of possible design strategies nowadays incorporated in design guidelines and codes [e.g., 34, 35, 36]. However, whilst a large number of studies have provided invaluable insights into important behavioral aspects, the approaches and procedures developed do not address the problem of retrofitting existing buildings to increase their progressive collapse resistance.

Most of the existing buildings worldwide, with a few exceptions, do not incorporate design provisions to achieve structural robustness and are susceptible to progressive collapse. Among others, steel structures are particularly vulnerable as they are usually optimized with respect to specific design actions and existing structures are often characterized by a relatively low level of redundancy. In this context, there is a significant need for the development of effective and efficient retrofit methods against progressive collapse.

To date, very few research studies have focused on mitigation strategies against progressive collapse through the enhancement of the overall structural capacity. In a progressive collapse scenario, there are some 'key elements' whose performances influence the evolution or halt of the damage spreading. Galal and El-Sawy (2010) [37], Lui (2010) [38] and more recently, Ghorbanzadeh et al. (2019) [39] investigated retrofit solutions that aim at increasing strength and 
stiffness of the beams and/or of beam-column joints in order to allow the development of catenary actions. The outcomes confirmed that in some cases, this upgrade provides improvements in progressive collapse resistance. Nonetheless, beam mechanism is not always the one that occurs first, and it also requires an inherent degree of structural redundancy that is often not provided in steel structures. Moreover, in several situations, due to the frame geometry and load configuration, the columns could represent the weak members in the system, and consequently, the enhancement of the beam performance would result in an ineffective intervention. Papavasileiou and Pnevmatikos (2018) [40] numerically investigated a retrofit solution against progressive collapse based on the introduction of steel cables within the frames on a few story levels. The analyses were performed on a 3D steel frame modeled in OpenSees [41] and allowed investigating the influence of several parameters on the effectiveness of the proposed retrofit solution. The results show how this system, if properly designed, can effectively provide improved performances by increasing the structure's redundancy. On the other hand, this approach drastically changes the structural dynamic behavior under horizontal actions, which could lead to significant detrimental effects on the seismic performance. In addition to the specific limitations highlighted above, the described approaches are both invasive, involve high costs and long business interruptions.

Another interesting solution, which is investigated in this paper, regards the construction of a truss at the rooftop level of the building. This 'roof-truss' is connected to the ends of all columns of the top floor: if properly designed, this strategy makes available further alternative load paths, providing a better redistribution process, without significant influence on the lateral stiffness distribution with the building's high. The motivations on support of this solution are: 1) it is a global retrofit measure that can in principle be applied to several structural typologies without relying on high redundant schemes; 2) the low influence on the seismic response, due to the roof position of the retrofit system and the small added mass; 3) the effectiveness against the column removal scenario by providing enough stiffness to involve a high number of columns in the alternative load path;4) the low invasiveness on the ordinary investigated a similar solution consisting of two different rooftop hanging systems: a top beam grid and a top gravity truss. Both solutions aim to compensate for the sudden reduction in vertical stiffness and strength with minimal effect on the seismic design. The author studied buildings with different floors number and seismic design actions, demonstrating the retrofit solution potential in increasing their progressive collapse resistance.

However, the introduction of the 'roof-truss' may entail some issues in the existing structure that needs careful consideration [43]. Among others, the column removal may induce tension forces in the upper columns, which may 
be higher than the yielding tension force of the section and/or of the column joint splices. Moreover, as the 'rooftruss' is able to redistribute the load to the other columns in terms of additional compressive load, they may fail because of buckling. A careful design of the 'roof-truss', by calibrating both its stiffness and strength, enables the control of the load path generated by the column loss scenario; hence, minimizing the local interventions, i.e., strengthening of column splices and measures to prevent buckling. Additional studies are required in this respect. Besides, the introduction of the 'roof-truss' influences the static but also the dynamic behavior of the system under the column collapse, i.e., influencing the Dynamic Increase Factor (DIF) [44], and this aspect needs a careful investigation. In fact, conventional design strategies rely on simplified methods based on static analysis accounting for the dynamic effects through the $D I F$, whose value could vary before and after the retrofit. Moreover, the $D I F$ provided in design codes is typically computed according to a ductile failure mode involving the plastic rotation of the structural element, component, connection, whereas the columns are omitted from the DIF calculation [35].

In the present study, the design of a 'roof-truss' retrofit system is investigated, providing several insights into the effectiveness of this mitigation strategy. The design procedure is based on the APM employed to simulate the initial loss and the consequential damage development by considering several column loss scenarios. In this way, the ability to provide a load redistribution among the other structural elements was thoroughly evaluated.

A 9-story steel Moment Resisting Frame (MRF) is considered as case study and modelled in OpenSees using a combination of finite element types and simulation methods to balance computational cost and accuracy. Key components of the numerical model, including the plastic hinges and the beam-column connections were validated against available experimental results to ensure reliable simulations. The validated models were then used to study the robustness of the building under a sudden column loss scenario. Both nonlinear static and dynamic analyses were employed. The simulations allowed for the identification of the possible failure modes and identification of the development of alternative load paths together with the definition of the DIF. The analyses outcomes showed how the proposed retrofit method allows increasing the performance of the case study structure under the progressive collapse scenarios simulated. Moreover, a parametric analysis is carried out on the 'roof-truss' to provide insights on the influence of the main design parameters.

The paper is organized as follows: Section 2 outlines the case study and the numerical modeling strategy; Section 3 describes the analyses procedures and the considered parameters; Section 4 describes the results of the static and dynamic analyses on the non-retrofitted structure under different column loss scenarios together with the definition of the $D I F$ for the several considered demand parameters and; Section 5 presents the design strategy for the roof-truss 
system through parametric analysis and the outcomes of numerical analysis on the retrofitted structure. Finally, in Section 6, conclusive remarks and future perspectives are drawn.

\section{CASE STUDY FRAME AND FINITE ELEMENT MODELLING}

122 The retrofit intervention's effectiveness and design procedure have been numerically investigated by considering a

123 building frame structure for case study purposes. The objective of the numerical analyses was to simulate the resisting 124 mechanisms involved in the progressive collapse scenarios, and hence, the evolution of the progressive collapse was

125 not a concern of this study. A Finite Element (FE) model was developed in OpenSees [41], and a mixture of finite 126 element types and analysis procedures were employed to balance accuracy and computational costs. Both geometrical 127 and mechanical non-linearities were included in the model.

\subsection{Case study frame}

The selected case study building is a 9-story Moment Resisting Frame (MRF) located in Greece and seismically designed according to the Eurocodes $[45,46,47]$ considering a peak ground acceleration equal to $0.16 \mathrm{~g}$. The building

131 is characterized by inter-story heights of $3 \mathrm{~m}$ and a total height of $27 \mathrm{~m}$. Only a plane frame is considered, and in the analyzed direction, the building has 4 bays of $5 \mathrm{~m}$ span while in the perpendicular direction, the bay span is equal to $7 \mathrm{~m}$. An overview of the structural elevation, including the main geometric parameters and section members is reported in Figure 1. Sections are oriented with the major axis within the frame plane, and rigid, full-strength welded beamcolumn joints were employed. The steel grade S235 is used with nominal yield strength $f_{y}=235 \mathrm{MPa}$, Young's modulus $E=210000 \mathrm{MPa}$ and Poisson ratio $v=0.3$. This frame was already considered as case study in previous research works focusing on progressive collapse [e.g., 48, 49, 50].

\subsection{Load combinations}

The dead load applied on the frame includes $3.00 \mathrm{kN} / \mathrm{m}^{2}$, corresponding to the self-weight of a $12 \mathrm{~cm}$ thick concrete slab, plus $2 \mathrm{kN} / \mathrm{m}^{2}$ to account for the presence of the non-structural permanent components. The total considered Dead Loads $(D L)$ is equal to $5.00 \mathrm{kN} / \mathrm{m}^{2}$ and is applied on all floors. The Live Load $(L L)$ was assumed of $2.00 \mathrm{kN} / \mathrm{m}^{2}$ and is applied on all floors except for the roof level. The Snow Load $(S L)$, applied on the roof floor, is assumed equal to $0.69 \mathrm{kN} / \mathrm{m}^{2}$, based on Eurocode guidelines [45] for the Greek climate region in Zone III, $200 \mathrm{~m}$ of altitude, where the

144 building is located, and standard conditions. According to the UFC [35], the progressive collapse resistance of the frame is assessed by considering the following load combination: 
147 Moreover, in the column loss scenario, the gravity loads for floor areas above the removed column are amplified 148 by the $D I F$ accounting for the dynamic contribution of the removal event. The value of the $D I F$ is recommended by the UFC [35] depending on the type of analysis performed, the target structural response level and expected ductility demand of beam elements in the area above the removed column. However, in the present study, the DIF was explicitly determined by the comparison of static and dynamic analyses.

152

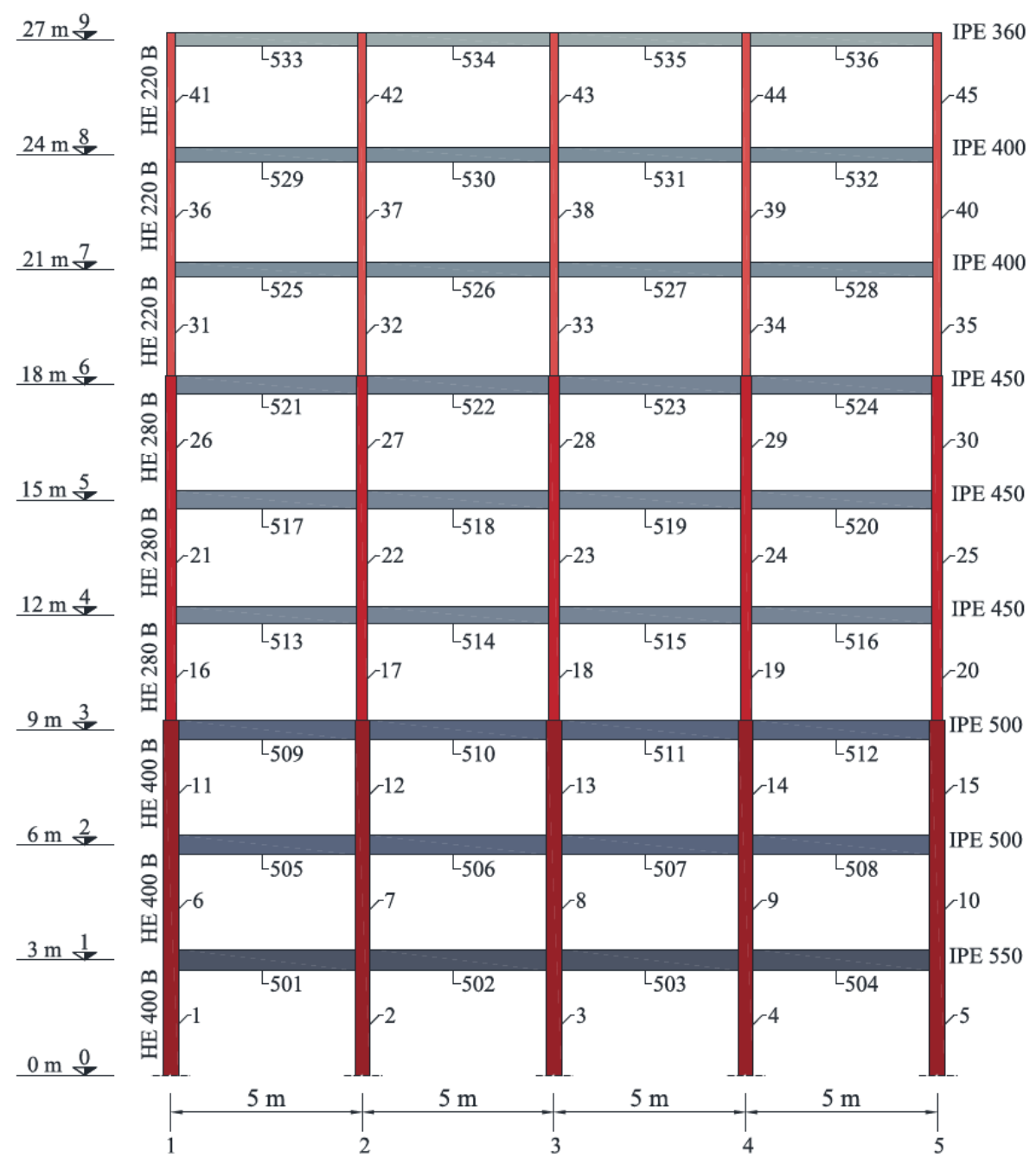

Figure 1. Geometry of the Case study (Adapted from Gerasimidis et al. [48]).

\subsection{Finite element modelling}

A 3D FE model of the plane frame was built to account for the possible out-of-plane flexural buckling about the columns' minor axis. The columns were modeled with 'force-based beam-column' elements [41] which rely on a distributed plasticity approach with a fiber formulation. This allowed accounting for the axial-flexural interaction, 
which characterizes the non-linear behavior of these members. The elastic shear stiffness was included through the 'section Aggregator' while both the in-plane and out-of-plane flexural buckling were modelled by introducing local and global equivalent imperfections recommended by Eurocode 3-1-1 [46].

On the other hand, beams were modelled through a lumped plasticity approach, combining 'elasticBeamColumn' elements with the 'Parallel Plastic Hinge' (PPH) model proposed by Lee et al. [51]. This model is able to account for the beam behavior in progressive collapse scenarios, which is characterized by flexural and axial actions rising in two different phases: 1) after the column removal the beam predominantly resists in bending and in shear; 2) then, when large deformations intervene catenary action develops and the resisting mode is mainly axial [52]. An illustration of the beam-column joint and the PPHs used in the beams is reported in Figure 2. The PPH model [51] aims to provide a computationally efficient macro-model for practical progressive collapse analyses. In the present work, such a system was calibrated and validated against experimental results [17] to increase the confidence in the numerical model. The validation phase is reported in Figure 3, where the results of the PPH model are compared with the experimental data. It is possible to observe that the pushdown curve and the axial tension force, in Figure $3 \mathrm{~b}$ and $\mathrm{c}$, respectively, are in good agreement, whereas the PPH model slightly underestimates the bending moment capacity (Figure 3d). However, the value of the maximum bending moment provided by the PPH model is consistent with the plastic resisting bending moment of an IPE section with measured yield strength as provided in Dinu et al. [17]. Several modelling strategies have been evaluated. The combination of elastic elements and PPH resulted in the best strategy in terms of accuracy (replicating experimental results) and computational effort.

In addition, as illustrated in Figure 2, the deformation of the panel zone of the beam-column joints was included by using the 'Scissors Model' [53]. As depicted in Figure 2, it consists of a set of two independent flexural springs, which simulate, respectively, the deformability of the column web panel and flanges. The springs connect two orthogonal rigid links, whose extension is consistent with the node's physical dimensions. The factors governing this system mechanical behavior were evaluated following the recommendation of recent research studies [54].

The present study neglects the possible positive contribution of the slab to the progressive collapse resistance as done in similar studies [e.g., 17, 19]. In particular, in the present study, this choice is justified by the fact that, while retrofitting an existing structure, the slab may not be composite and limited information may be available to estimate its contribution, and hence conservative assumptions are required. Moreover, in both beams and columns, lateraltorsional buckling was not taken into account directly in the model; however, it was checked a posteriori, based on the recommendations of the Eurocodes confirming that in the analyzed cases, this simplification did not affect the 


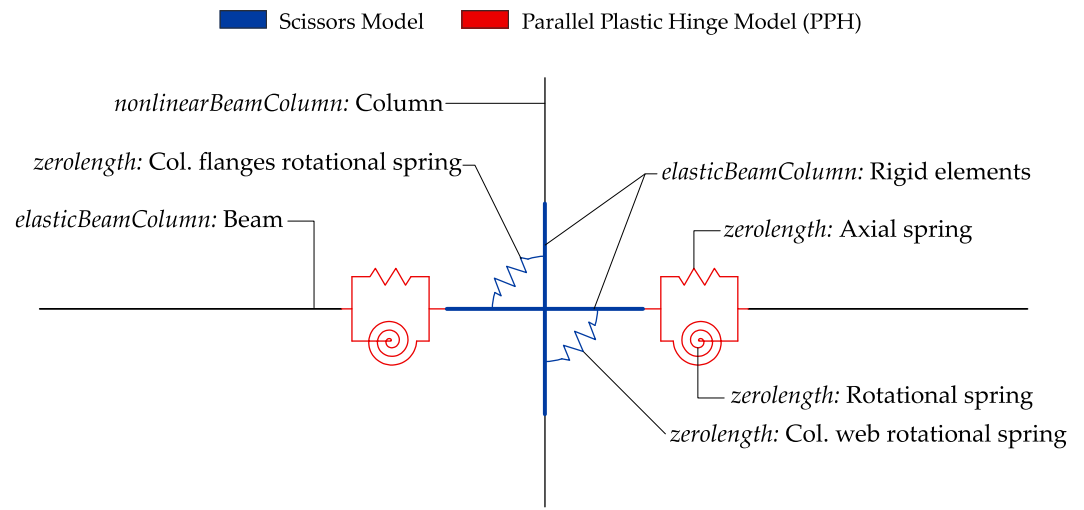

Figure 2. Model of the Beam-column joint.

a)

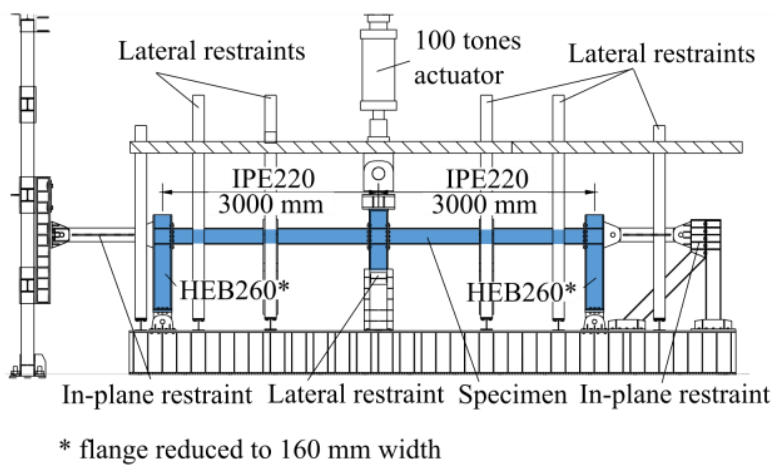

c)

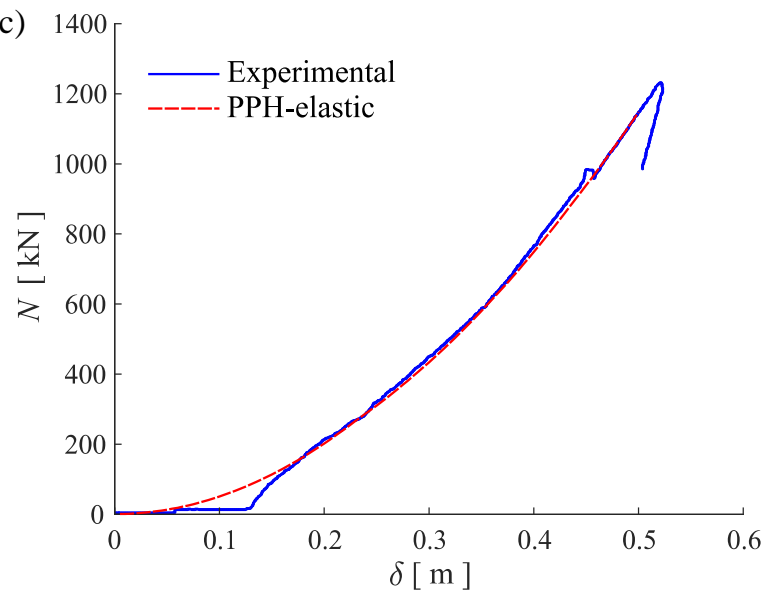

b)

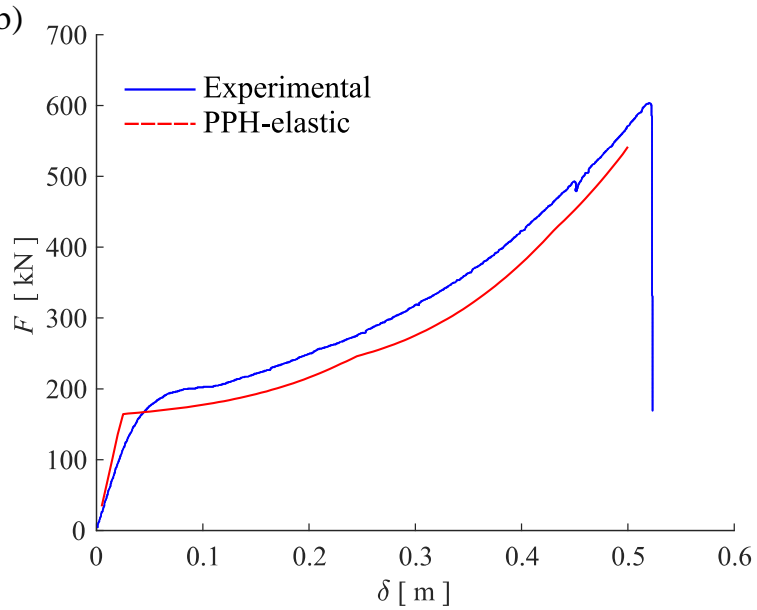

d)

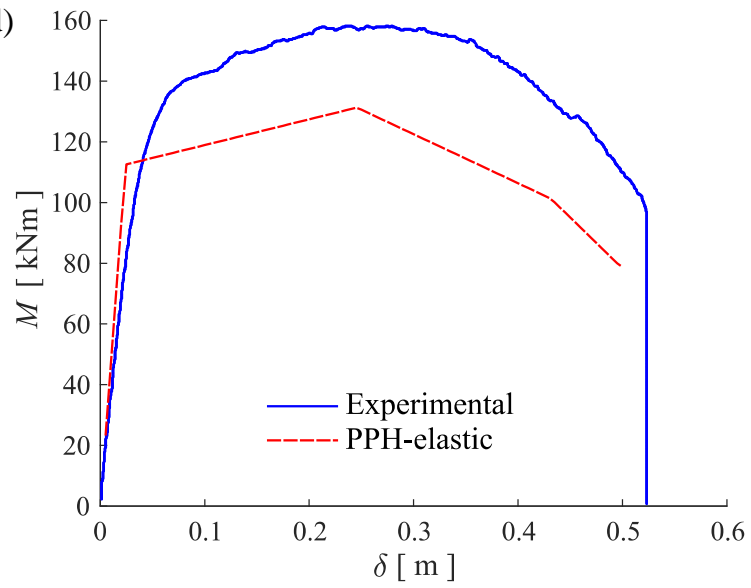

Figure 3. Numerical model validation for the beam-column joint. (a) Experimental setup from Dinu et al. [18] and experimental vs. numerical results for: (b) pushdown curve; (c) axial tensile force at beam end; (d) bending moment at beam end.

In order to simulate the resisting mechanisms occurring in large displacement analyses, such as catenary action, the 'Corotational' formulation was employed in the analyses. 


\section{ANALYSIS PROCEDURES}

196 The analysis of the load redistribution as a consequence of the column loss scenario was performed based on the APM

197 [36] and considering both non-linear static and dynamic analysis performed according to the UFC guidelines [35].

198 Moreover, the comparison between the non-linear static and dynamic analyses allowed the definition of the DIF for

199 the existing structure and the evaluation of the DIF variation as a consequence of the retrofit. The numerical

200 simulations allowed: 1 ) the assessment of the vulnerability of the existing structure under the two main column loss

201 scenarios; and 2) the evaluation of several aspects related to the 'roof-truss' intervention.

\subsection{Non-linear static analysis}

203 The non-linear static analysis indirectly accounts for the dynamic effects through the DIF. Figure 4 shows the three 204 steps required for the non-linear static analysis by considering the central column loss scenario. The 'Preliminary 205 Analysis' (Figure 4a) of the undamaged structure allows defining the force distribution in all the structural members 206 under the progressive collapse design load combination. This step provides the axial force carried by the column where

207 the removal is simulated. Successively, the progressive collapse analysis is performed in two additional successive steps. Firstly in the 'Standard Analysis' (Figure 4b), the selected column is removed from the numerical model, and

209 its presence is simulated by an upward point force $R_{c}$ applied at Node A, whose intensity is equal to the axial force 210 obtained in that column in the 'Preliminary Analysis'. The gravity design loads and the point force $R_{c}$ are applied to 211 the structure and linearly increased together. It was assessed, considering different scenarios, that for the considered 212 case study, neglecting the other reaction components, i.e., shear force and bending moment, of the removed column 213 did not cause significant variation in the redistribution process. In the successive step, named 'Removal Analysis' 214 (Figure 4c), the removal of the column is simulated through the application of a counterforce $F_{c}$ at Node A, with the 215 same magnitude but opposite direction of $R_{c} . F_{c}$ is linearly increased together with the additional loads applied on the 216 bays above the removal, which account for the $D I F$. When the force $F_{c}$ is totally applied, the removal is deemed 217 completed, and the structure is therefore capable of withstanding the column loss. Conversely, if no equilibrium is 218 attained before the removal process is completed, the structure is deemed not robust enough to resist the column loss.

\subsection{Non-linear dynamic analysis}

220 The non-linear dynamic analysis is also performed in three steps. The first two steps are identical to the 'Preliminary 221 Analysis' and 'Standard Analysis' steps described above (Figure 4a and b). The third step is different since the 
counterforce $F_{c}$ is increased from 0 to $100 \%$ of its value within a defined, and 'short', Removal Time $\left(T_{\text {Rem }}\right)$. According to GSA guidelines [36], column removal time should be less than $1 / 10$ of the period of the vertical vibration mode $\left(T_{v}\right)$ of the structure. In this study, $T_{\text {Rem }}$ was assumed equal to (1/11) $T_{v}$. Moreover, differently from the static analysis case, careful modelling of the masses and of the damping was required to correctly capture the dynamic effects. In this case, masses were concentrated at regular intervals along the beams for a total of 297 masses distributed on the 4 bays at all stories (i.e., 33 masses at each story of which, 5 at beam-column joints and 7 within each beam). It has been verified that a higher discretization of the mass does not produce significantly different results. Besides, Rayleigh damping with a damping ratio $\xi$ equal to $5 \%$ was employed and defined for the two representative modes of vibrations involves the area above the removal $\omega_{v}$.

a)

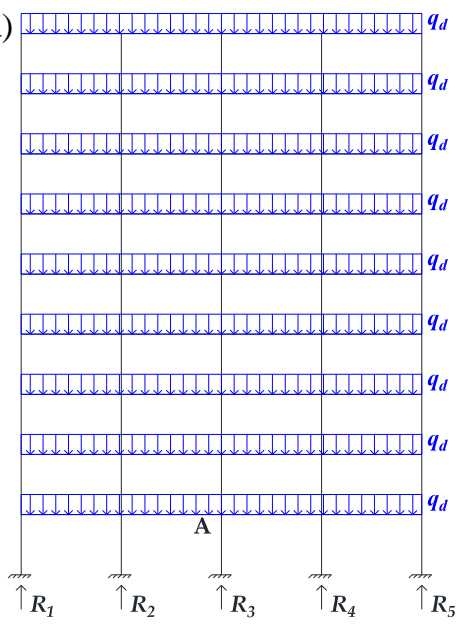

b)

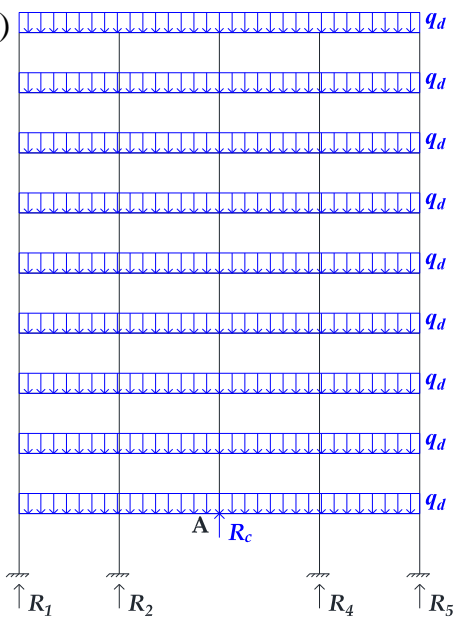

c)

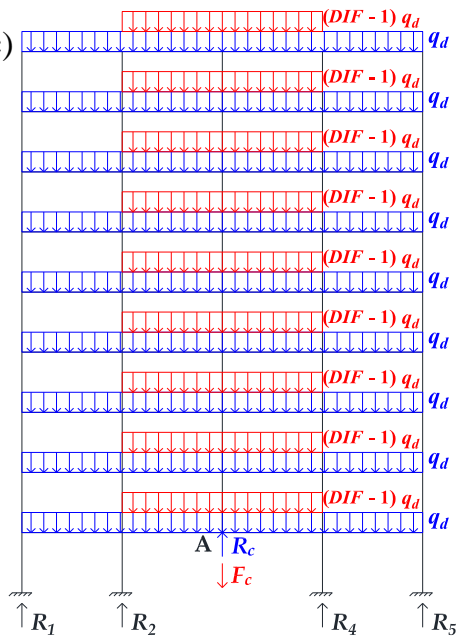

Figure 4. Analysis procedure for the non-linear static analysis for the central removal column scenario. (a) 'Preliminary Analysis' of the undamaged structure with gravitational loads for the definition of reaction and internal forces; (b) 'Standard Analysis' with element removal and reaction force $R_{c}$; c) 'Removal Analysis' with the counterforce $F_{c}$ and the increased distributed load with the DIF.

\subsection{Engineering Demand Parameters (EDPs) and Load Factor coefficient ( $\lambda$ )}

Several Engineering Demand Parameters (EDPs) and the Load Factor coefficient $(\lambda)$ were used in order to monitor the state of progress of the removal event. The coefficient $\lambda$ was defined as:

$\lambda=\frac{\sum_{i=1}^{n} R_{i}}{Q_{t g}}$

241 where $\sum_{i=1}^{N} R_{i}$ is the sum of the vertical base reaction forces of the frame, and $Q_{t g}$ is the load target the structure is 242 supposed to bear in the specified situation. When $\lambda$ reaches the unitary value, all the loads applied have found an 
alternative path to the ground, and the removal event is completed. If any failure is detected in the structure for $\lambda$ values lower than 1 , then the structure is not able to redistribute the load for the damage scenario investigated, highlighting the need for retrofit measures.

In addition, local EDPs were defined to monitor the performance of beams and columns. The beam performance was monitored by comparing the chord rotation demand $\theta_{b}$ with the limit value for plastic rotation $\theta_{p r a}$ of primary beams defined by the acceptance criteria of the UFC [35]. The present case study uses welded unreinforced flanges connections leading to a plastic rotation angle of $\theta_{\text {pra }}=0.0284-0.0004 h$, where $h$ is the beam depth. It is worth mentioning that the displacement of node $\delta$ corresponding to the removed column is proportional to the chord rotation. On the other hand, to monitor columns performance, the Work Ratio coefficient $(W R)$ was defined as the ratio between the axial force $N$ and the value that would cause failure (i.e., yielding or buckling) in that element $N_{b}$. This indicator is not precise because the columns are generally subjected to axial force and bending moment. However, in the columns at the base, which are more prone to buckling, the axial load is dominant. Besides, it is worth highlighting that the modelling strategy implemented, from one side accounts for the interaction between moments and axial forces (i.e., distributed plasticity), from the other side is able to capture buckling in both the element axis due to the modelling of the imperfections. Additionally, to better understand the column behavior, the relative horizontal displacements of the column middle node, both in-plane $\left(u_{x}\right)$ and out-of-plane $\left(u_{z}\right)$, were also monitored.

\subsection{Dynamic Increase Factor (DIF)}

A direct way to evaluate the DIF consists of performing both non-linear static and dynamic analyses on the structure while monitoring the EDPs that characterize the structural behavior under progressive collapse. The $D I F$ is then calculated as the ratio of the same response parameter for the two analyses, e.g., for chord rotations or nodal displacements for beams and axial forces for columns. In this case, the static analysis considers only the actual (i.e., non-amplified) loads on the beams.

The DIF to be considered depends on the system most vulnerable component and on the progressive collapse scenario considered. Beams reach their maximum bearing capacity due to excessive plastic deformation at beam ends and/or in the beam-column connections. Conversely, columns can be subjected to buckling or yielding due to excessive axial load or a combination of the axial load with the other actions. In order to achieve the objective of simulating the dynamic amplification within a static analysis and depending on the considered situation, the $D I F$ should be calibrated to statically reproduce the same values of the EDP, i.e., chord rotation, node displacement, or 
axial forces, obtained by the dynamic analysis. In the present study, two different DIFs are calculated, respectively,

272 for beams and columns based on the following equations:

$$
D_{\delta}(\lambda)=\frac{\delta_{D}(\lambda)}{\delta_{S}(\lambda)} \quad ; \quad D_{N}(\lambda)=\frac{N_{D}(\lambda)}{N_{S}(\lambda)}
$$

where the subscripts $D$ and $S$ are related to the dynamic and static derivation, while $\delta$ and $N$ are the displacement at the node above the removal and the axial load in the column adjacent to the one removed. The DIFs can be expressed as a function of $\lambda$, however, the DIFs corresponding to the load increment relative to collapse $\left(\lambda_{U}\right)$ should be used in the design.

Further considerations are required for the $D I F_{N}$. In fact, according to the UFC [35], the $D I F$ amplifies only the loads on the bays above the removed column. Conversely, according to the above-described procedure, the $D I F$ is evaluated by progressively incrementing a uniform load on all the spans. Hence, to statically simulate the demand in terms of axial force in the columns, consistency between the formulations needs to be restored. The introduction of a new $D I F_{N}{ }^{*}$, applied only to those few beams, allows for reproducing the same stress state in the adjacent columns obtained in the uniform-load analysis. An approximated formulation for the calculation of the $D I F_{N}{ }^{*}$ is proposed:

$$
D I F_{N}^{*}=1.425 D I F_{N}-0.425
$$

Eq. (4) is based on the following assumptions: 1) four equally long and loaded spans are considered; 2) same axial stiffness at the supports; and 3) removal of the central column. These assumptions represent the typical conditions for the collapse of an internal column. In particular, despite only four spans are considered here, the proposed equation represents a 'good' approximation also for cases with a larger number of spans. In fact, the contribution provided by additional spans, farther from the collapse location, is usually negligible [15]. In greater detail, Eq. (4) was determined by imposing the equivalence in terms of reaction forces $R_{2}$ and $R_{4}$ between the two schemes presented in Figure 5 and the principles of structural analysis were applied to solve the system of the two continuous beams so as to obtain the unknown value of $D I F^{*}{ }_{N}$. Validation of the above-described procedure for the derivation of the $D I F$ is provided in Section 4.

\section{ANALYSIS OF THE EXISTING CASE STUDY STRUCTURE}

\subsection{Non-linear dynamic analysis and Dynamic Increase Factor (DIF)}

For the DIF derivation, the dynamic analyses were performed in an Incremental Dynamic Analysis (IDA) fashion for 
increasing values of the coefficient $\lambda$ with constant increments equal to 0.05 . The results of the IDA for different $\lambda$ values and in terms of node displacement history for the central column loss scenario are shown in Figure 6a. Similar results for the axial force in the column adjacent to the removed one are shown in Figure 6b. It is worth mentioning that the mass is increased proportionally to the load, and this causes an increase of the vibration period. Moreover, despite Figure 6 shows the response for $\lambda$ until the value of 1 , for load increments with $\lambda=0.90,0.95$ and 1.00 , the axial demand of the columns adjacent to the removed one exceeds their axial buckling resistance as indicated by the red symbol in Figure 6. Figure $6 \mathrm{c}$ and d show the horizontal displacements of the column middle nodes respectively in the $x$-direction (i.e., $u_{x}$ ) and z-directions (i.e., $u_{z}$ ) highlighting the column buckling.

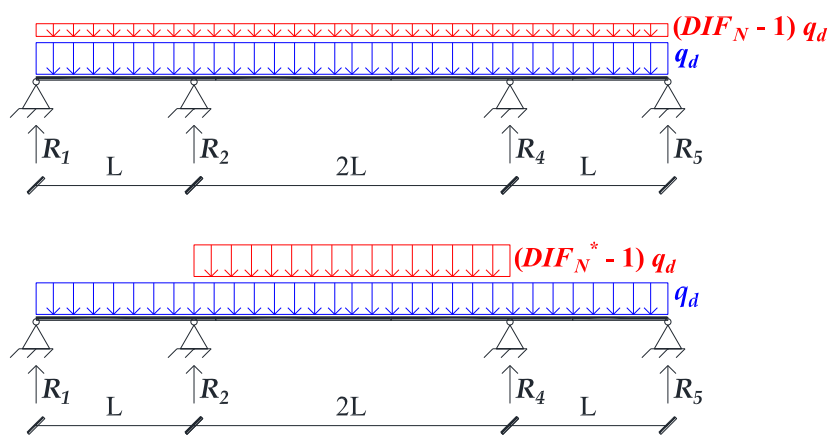

Figure 5. Static schemes for the definition of an approximated formulation of the $D I F_{N}{ }^{*}$.
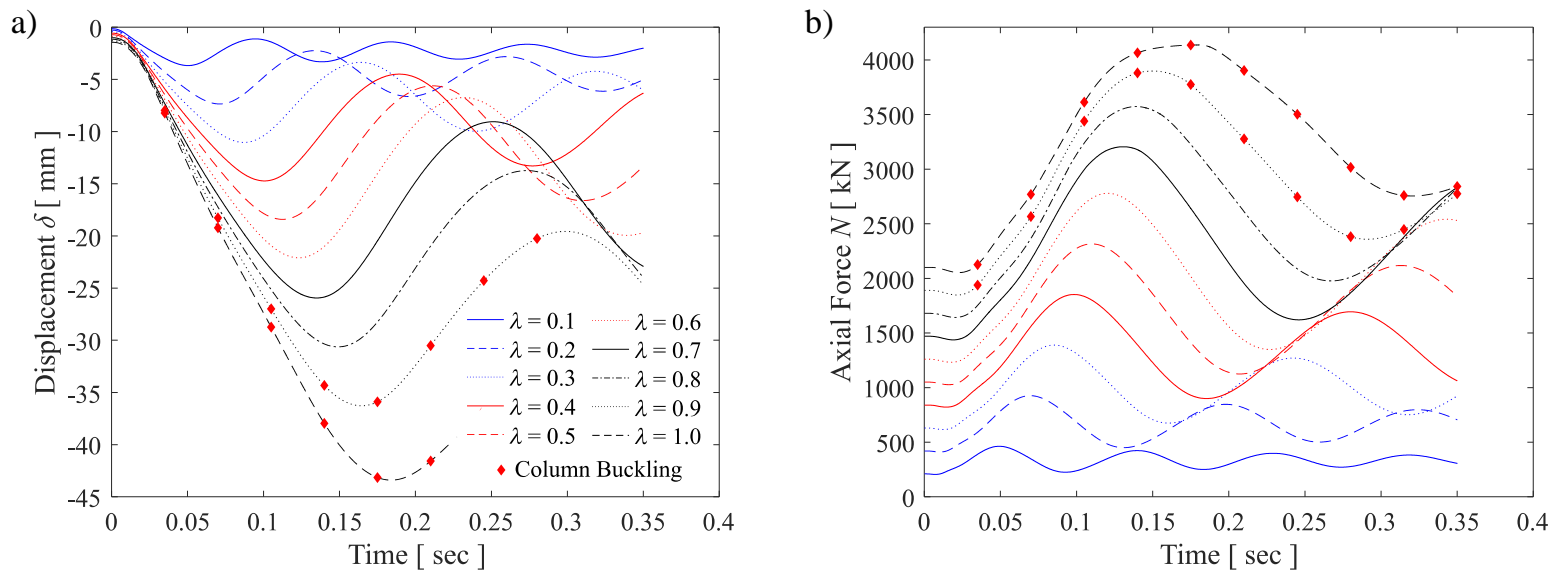

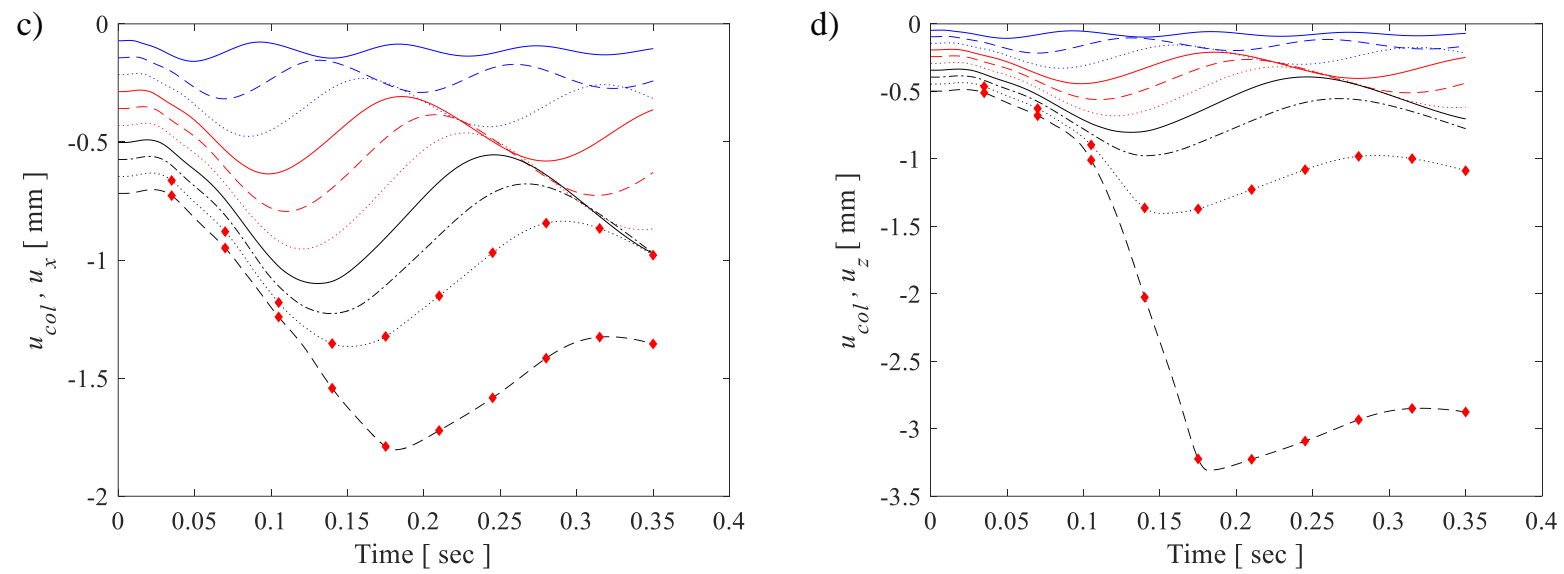

Figure 6. Time histories for the Incremental Dynamic Analysis (IDA) for the central loss column scenario for: (a) node vertical displacements $\delta$; Response of Column 2 with (b) axial force $N$; and horizontal displacements of the column middle nodes in the (c) $x$-direction (i.e., $u_{x}$ ) and (d) $z$-directions (i.e., $u_{z}$ ).

The non-linear static analysis for the same column loss scenario has been performed in order to allow the comparison of the results and the definition of the DIFs. It is worth reminding that, in this case, the static analysis considers only the actual (i.e., non-amplified) loads on the beams. In both static and dynamic cases, the progress of the analysis can be read in terms of load factor $\lambda$. Figure 7 and Figure 8 show the results of both the dynamic and static analyses and the DIFs calculation for the central column loss scenario. Similar considerations have also been done for the other column loss scenarios but are not reported here for the sake of brevity. Figure 7 shows the evolutions of the vertical displacement $\delta$ and the axial force $N$ versus the load factor $\lambda$. It is possible to observe that performing a non-linear static analysis without accounting for the dynamic effects, i.e., $D I F=1.00$, the structure would withstand the removal of the central column because equilibrium up to $\lambda=1.00$ is achieved. However, the non-linear dynamic analyses show that it would not be the case; thus, a careful investigation is required. Figure 8 shows the values of the DIFs for both beams and columns calculated according to Eq.s (3). It is interesting to note that the DIF computed for the axial force $N$ in the columns, i.e., $D I F_{N}$, is more meaningful because, for the considered case study structure, it is associated with the actual failure mode under progressive collapse scenarios. Moreover, it is worth highlighting that the $D I F$ obtained for the beams, i.e., $D I F_{\delta}$, is significantly higher than the one proposed by the UFC guidelines [31], which, for the current structure, would have been equal to 1.24 . This is related to the different failure mode observed in the present case study. In fact, the UFC guidelines [31] provide a DIF value based on beam-type collapse. This kind of failure is usually highly ductile, as it requires all beams have entered the plastic field, with large energy dissipation.

On the other side, the column-type collapse, i.e., attainment of the buckling strength, occurs with the beam still in the elastic range, which explains, as a consequence, the outcome of higher $D I F_{\delta}$ values compared with the ones from the 
codes.
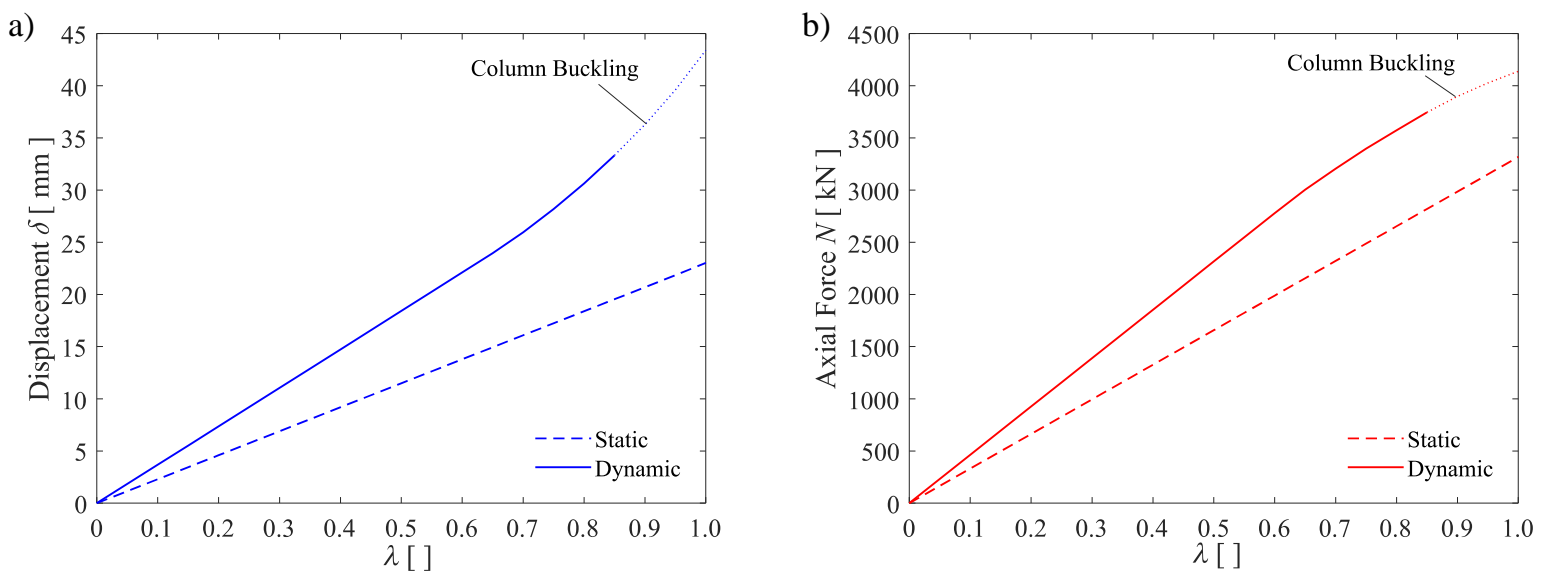

Figure 7. Comparisons of non-linear static and dynamic response parameters for DIF calculation for: (a) node

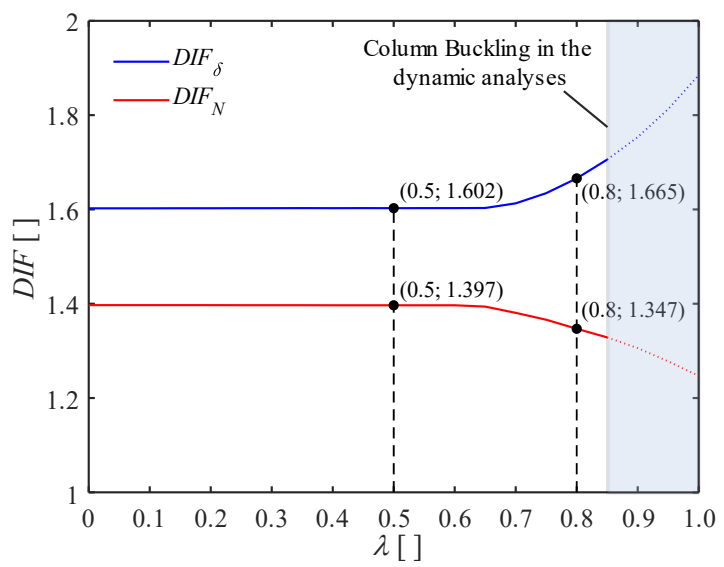

Figure 8. DIF calculation for the existing case study structure for $D I F_{\delta}$ and $D I F_{N}$.

The procedure described in Section 3 for the DIF derivation has been validated as described in the following. Two $\lambda$ values have been selected, i.e., $\lambda_{1}=0.5$ and $\lambda_{2}=0.8$ and the corresponding $D I F_{\delta}$ and $D I F_{N}$ have been used for validation purposes. Through these values, static analyses have been performed, allowing the comparison with the EDPs values obtained based on the dynamic analysis procedure.

Figure 9 shows the comparison, respectively, for node displacement $\delta$ and axial force $N$, for different $\lambda$ values. It is reminded that, since the DIFs vary for $\lambda>\sim 0.6$, the comparisons here proposed have validity only in correspondence to $\lambda_{1}$ (Figure 9a and b) and $\lambda_{2}$ (Figure 9c and d). In this case, the static analyses have been performed with a load amplified by the DIF applied on all bays; this process consists exactly in the reverse process with respect to the one used for the DIFs evaluation. Figure 9 shows that a match of the results is obtained in correspondence of $\lambda_{1}$ and $\lambda_{2}$ 
demonstrating the adequacy of the used methodology for the DIF calculation. The only exception is Figure 9c related to node displacement for $\lambda_{2}=0.8$. This is the consequence of the large value of the $D I F_{\delta}=1.665$ that induces structure incipient collapse in the static analysis, that is governed by column buckling and not by chord rotation demand of the beams.

However, the UFC guidelines [35] recommends the incremented load to be applied only on the adjacent-to-removal spans. This approach has also been tested, and the results are described in the following. Figure 10 shows the comparison, respectively, for node displacement $\delta$ and column axial force $N$, for different $\lambda$ values. Figure 10a shows how this approach approximates well the chord rotation demand in the beams demonstrating the low sensitivity of the beam response to the load on the adjacent spans and the adequacy of the method proposed by the UFC [35]. Conversely, as previously observed (in Figure 9c) also in this case, Figure 10c highlights how the large value of the $D I F \delta$ induces structure incipient collapse in the static analysis as consequence of the column buckling. Figure 10b and d demonstrate how this approach is not appropriate to correctly simulate the column axial force, as discussed in Section 3. Moreover, it is noteworthy that this approach underestimates, approximately of $10 \%$, the axial force $N$, and hence it is unconservative with respect to the safety checks.

The approximate formulation for the $D I F_{N}{ }^{*}$, discussed in Section 3, and proposed to improve the axial force $N$ evaluation through non-linear static analysis, has been tested and presented in the following. Figure 11 shows the comparison, for the axial force for different $\lambda$ values by considering the modified $D I F_{N}{ }^{*}$ with incremented load applied only on the adjacent-to-removal spans. It can be observed that a perfect match is not obtained also in this case due to the assumptions used for the definition of the formulation for $D I F_{N}{ }^{*}$. However, the results show that, differently from forces $N$ by approximately of $10 \%$.
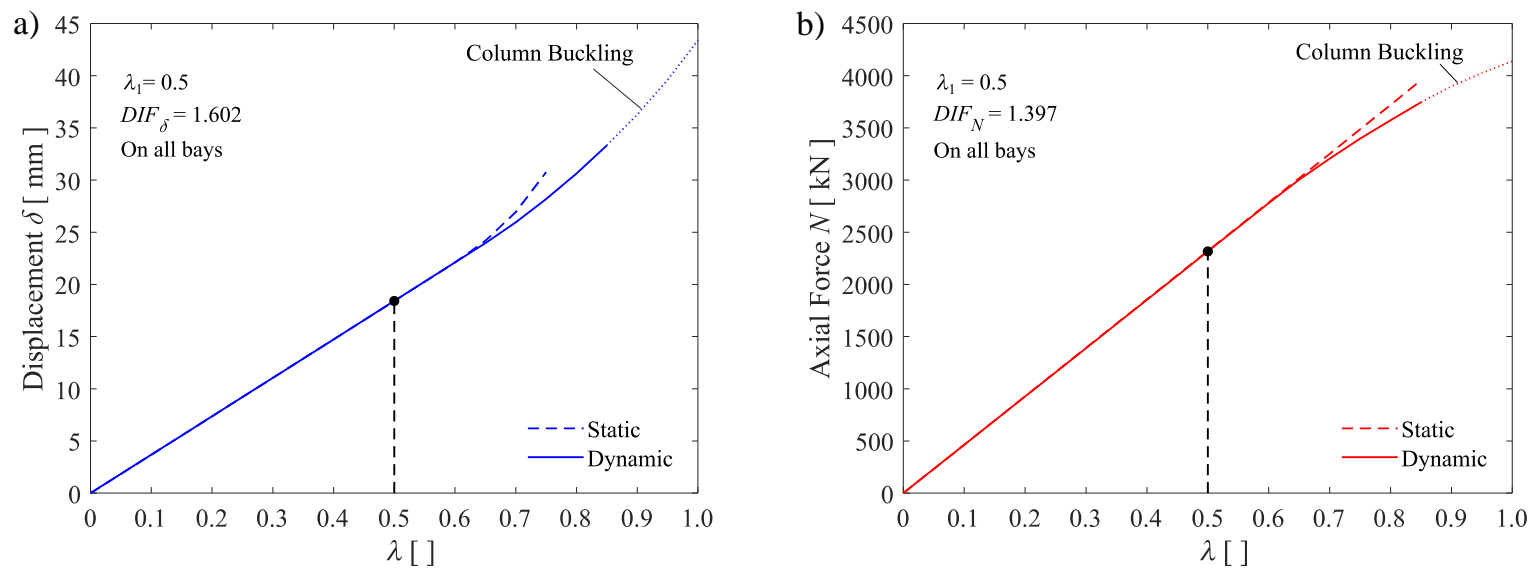

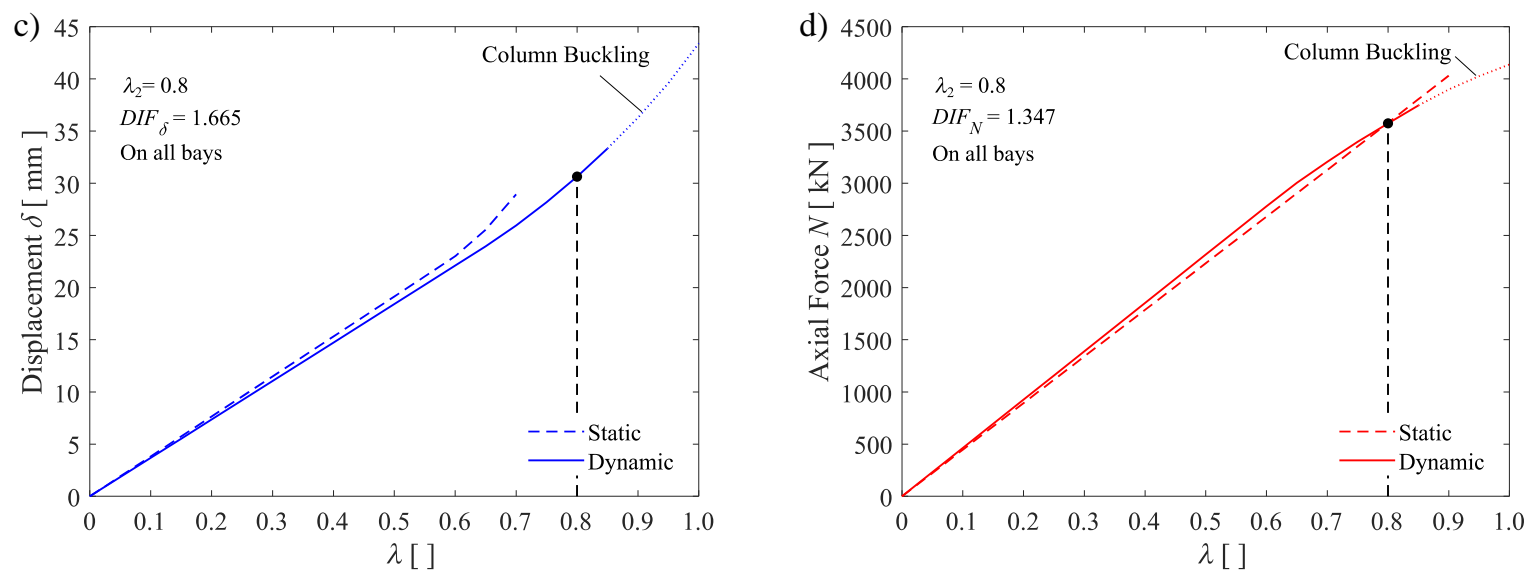

Figure 9. Validation of the $D I F$ procedure with increased loads applied on all bays. $\lambda_{1}=0.5$ for (a) node displacement $\delta$ - DIF $\delta=1.602$; (b) axial force $N-D I F_{N}=1.397 ; \lambda_{2}=0.8$ for (c) node displacement $\delta$ - DIF $\delta=$ $1.665 ;$ (d) axial force $N-D I F_{N}=1.347$.
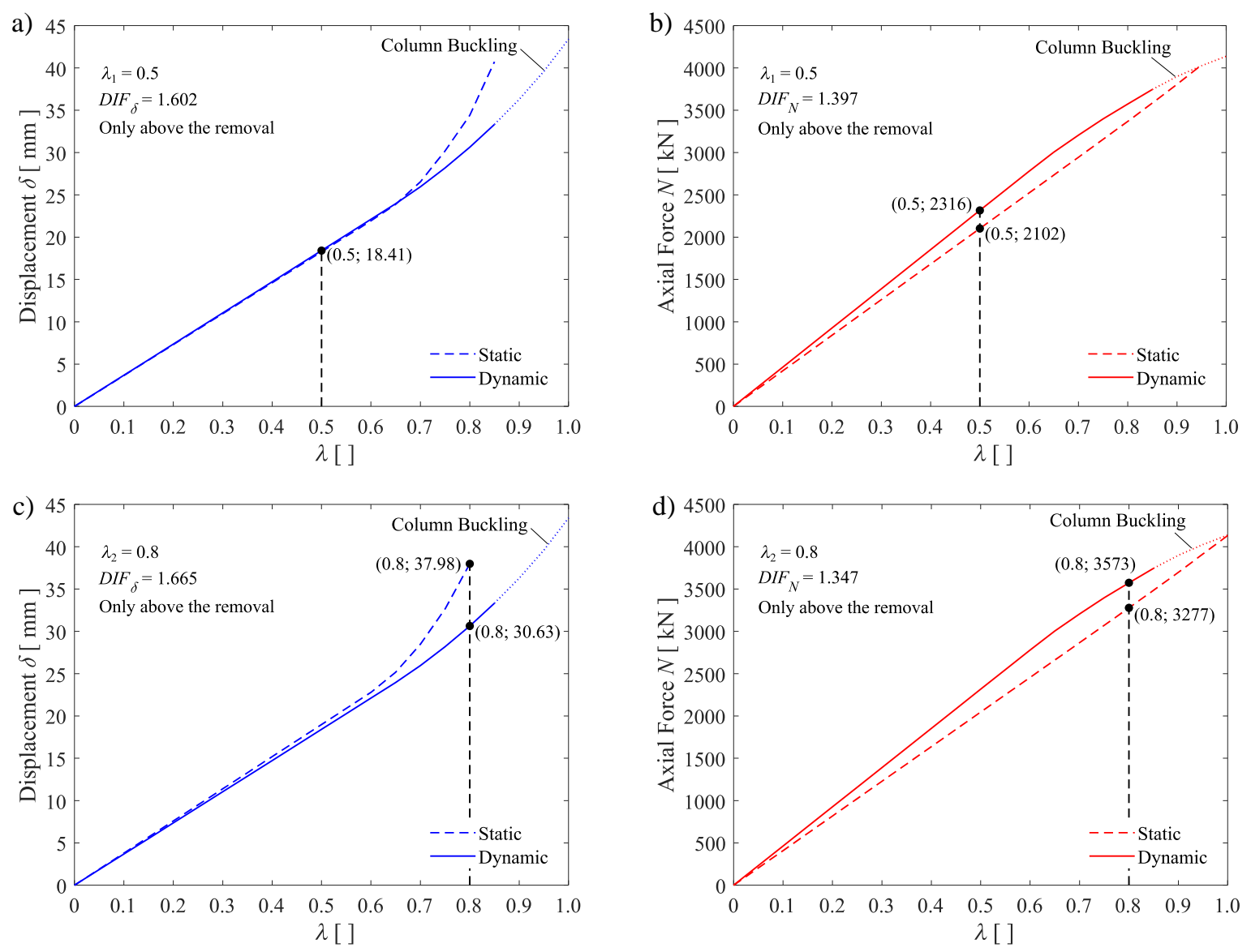

Figure 10. Validation of the $D I F$ procedure with increased loads applied only above the removal. $\lambda_{1}=0.5$ for (a) node displacement $\delta$-DIF $=1.602$; (b) axial force $N-D I F_{N}=1.397 ; \lambda_{2}=0.8$ for (c) node displacement $\delta$ - DIF $F_{\delta}=$ 

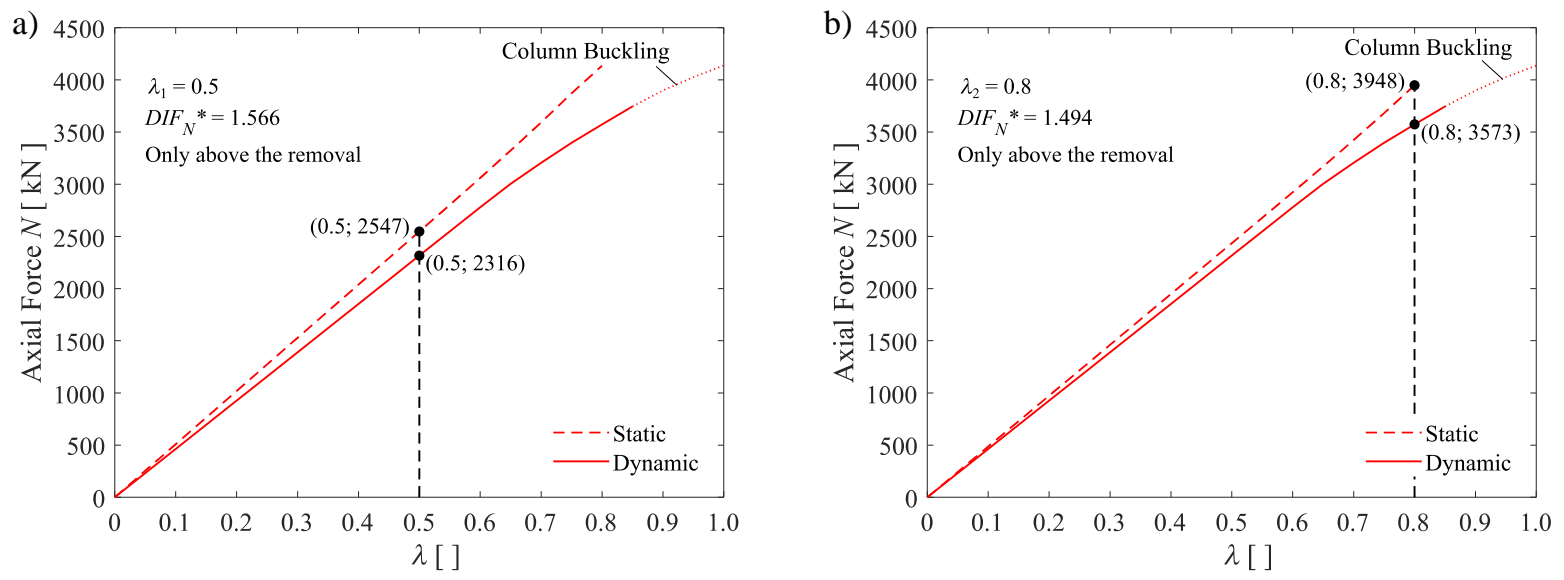

Figure 11. Validation of the DIF procedure for the axial force $N$. (a) Static Analysis for $\lambda_{1}=0.5$ with $D I F_{N}=1.397$ $\rightarrow D I F_{N}{ }^{*}=1.566$ applied only above the removal; (b) Static Analysis for $\lambda_{2}=0.8$ with $D I F_{N}=1.347 \rightarrow D I F_{N}{ }^{*}=$ 1.494 applied only above the removal.

\subsection{Non-linear static analyses}

The non-linear static analyses of the existing structure were performed by following the procedure suggested by the UFC [35] (i.e., with incremented load applied only on the adjacent-to-removal spans) but using the DIFs defined as described in the previous section. The dynamic analysis highlighted the columns as the weakest structural element: when the most stressed column exhibit buckling, the beam above the removal merely reaches the plastic moment, while all other ones remain in the elastic field. Based on this evidence, $D I F_{N}{ }^{*}=1.566$ was considered for the study of the existing structure.

The beam checks for $\lambda=1$, are reported in Figure 12. In particular, Figure 12a shows the comparison between the demand $\left(M_{d}\right)$ and the plastic $\left(M_{p l}\right)$ bending moment, while Figure 12b shows the comparison in terms of demand $\left(\theta_{d}\right)$ and the plastic $\left(\theta_{p l}\right)$ rotation. It can be observed that the beam rotation demand is far from reaching the maximum rotation capacity while only a few beams slightly overpass their plastic resistance. The small involvement of the beams can be also observed in Figure 13 that shows the ratios between the demand and the plastic capacity for the moment and axial force of the 502 beam left end (see Figure 1 for beam labels). The results show a relatively low participation of beams which slightly overstep the plastic moment, while catenary action is still absent. 

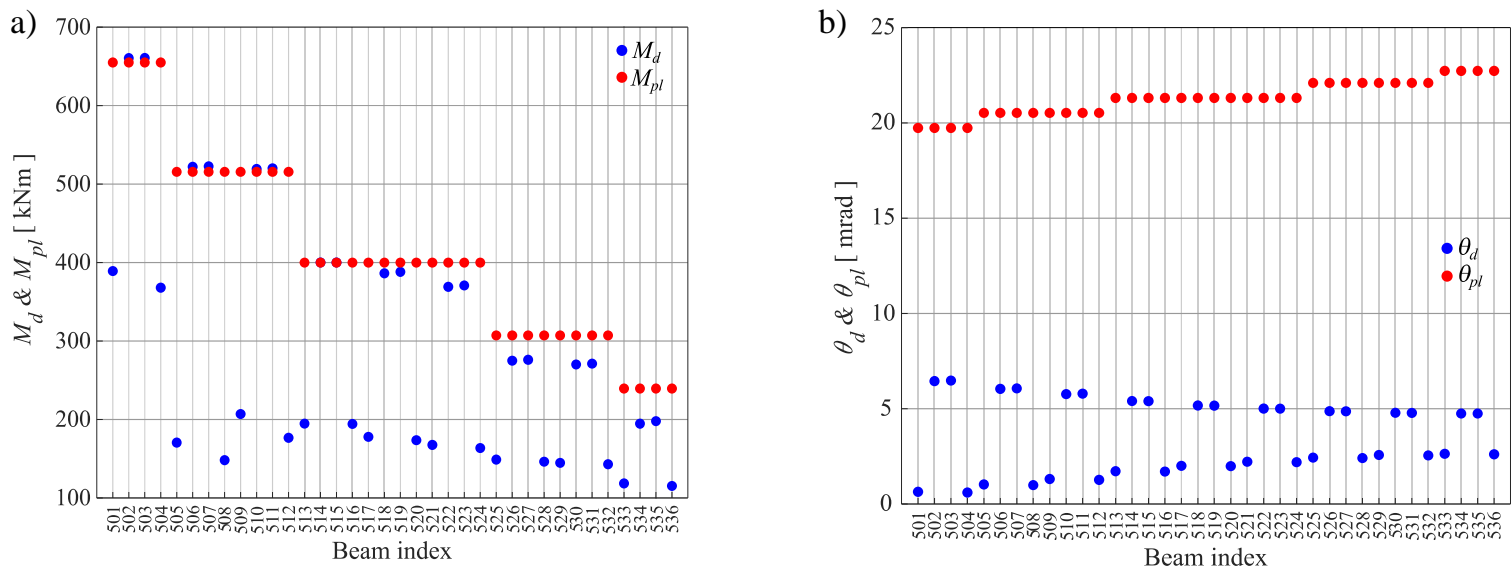

Figure 12. Moment and rotations of all beams of existing structure vs. UFC [35] acceptance criteria.

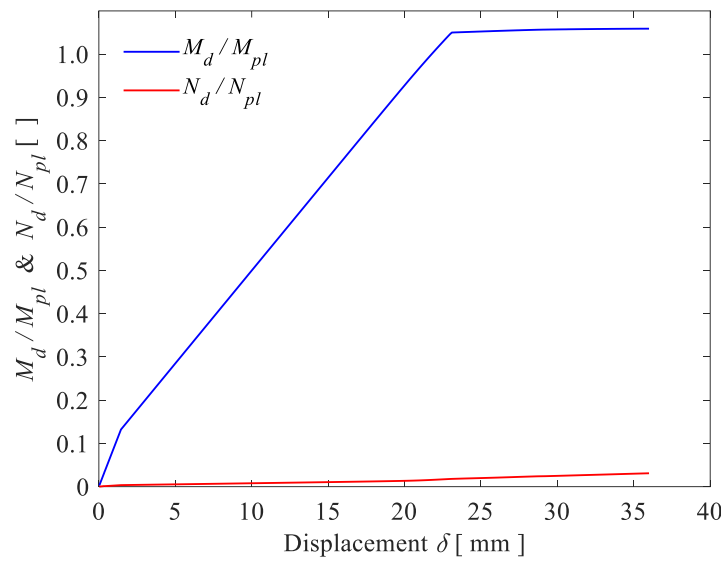

Figure 13. Internal stresses of most stressed beam (i.e., beam 502 left end) in the existing structure.

Figure 14 shows the column axial force distribution before and after the column removal. Due to symmetry conditions, only column lines 1, 2 and 3 are shown in the figure. It can be observed that the column removal generates a significant increase in axial force in the columns as a consequence of 1) load redistribution on a smaller number of structural elements; 2) the dynamic effects, i.e., the application of the DIF. The axial force increase is observed in the columns adjacent to the removal (i.e., column lines 2 and 4), while the further ones (i.e., column lines 1 and 5) are

397 slightly unloaded showing a small variation of the axial load before and after the removal. 

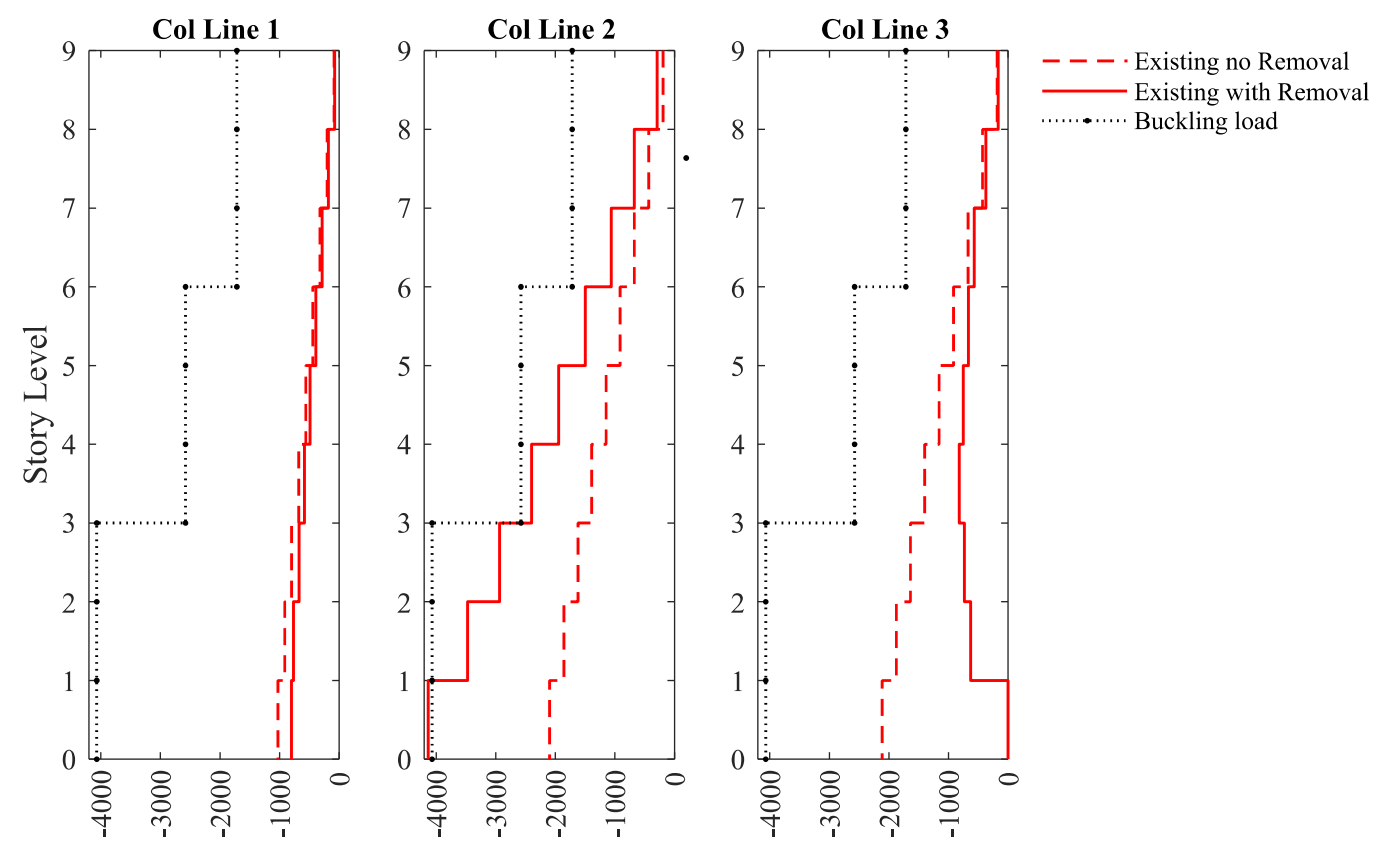

Axial Force $N[\mathrm{kN}$ ]

Figure 14. Columns axial force distributions before and after the column removal.

Figure 15 shows the performance of the structure and of the most critical columns (i.e., columns 2, 4, 17 and 19 as shown in Figure 1) during the column removal. Figure 15a shows the variation of the load factor $\lambda$ and of the WRs of the most critical columns vs the vertical displacement above the removal $\delta$. For simplicity and due to symmetry conditions, only columns 2 and 17 are reported. In the graph, the two steps of the analysis (i.e., 'Standard Analysis' and 'Removal Analysis' described in Section 3), can be recognized by the different stiffness. In the 'Standard Analysis', the presence of the column where the removal scenario is simulated, explains the stiff branch. As can be observed by Figure $15 \mathrm{a}$, the load factor $\lambda$ cannot reach the unitary value before the most stressed member exhibits failure (i.e., the WR of column 2 reaches the unit value before $\lambda$ ), meaning that the removal event could not reach the conclusion and the load could not be completely applied, as already discussed in Section 4.1 for the non-linear dynamic analyses. Figure $15 \mathrm{~b}$ shows the horizontal displacements of the column middle nodes in the $\mathrm{x}$ - and $\mathrm{z}$-directions (i.e., $u_{x}$ and $u_{z}$ ) highlighting the weak-axis flexural buckling of column 2. The results of the non-linear static analysis of the existing structure thus highlights the need of retrofitting in order to increase the structure robustness. 
a)

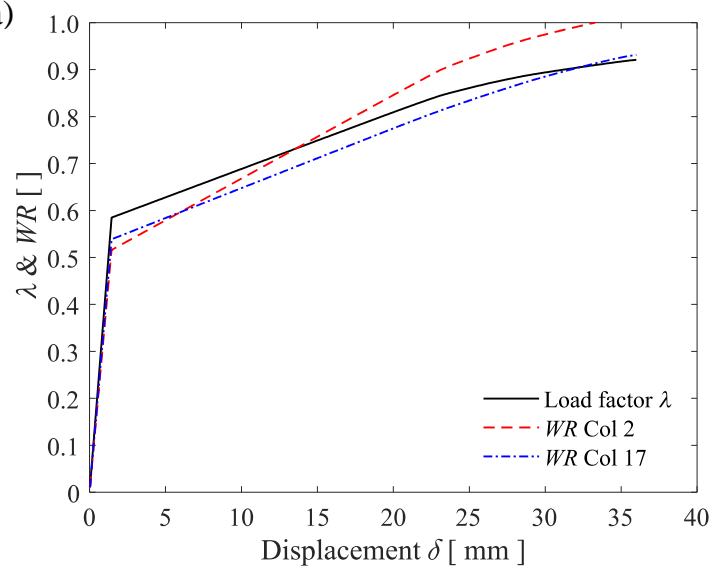

b)

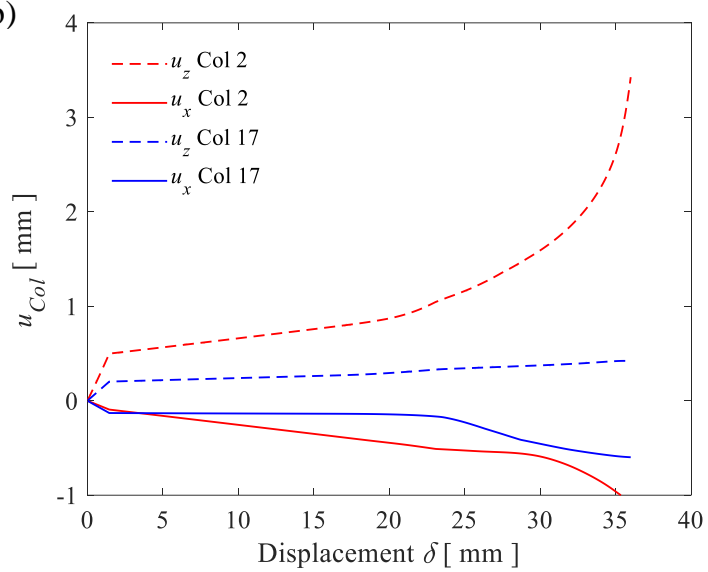

Figure 15. Results of removal analysis of existing structure: (a) load factor $(\lambda)$ and the $W R$ of the most stressed columns; (b) horizontal displacements of column middle nodes $\left(u_{\mathrm{Col}}\right)$ of existing structure.

\section{PROGRESSIVE COLLAPSE OF THE RETROFITTED CASE STUDY STRUCTURE}

The investigated retrofit intervention consists in the construction of a truss system at the roof level, i.e., 'roof-truss', connected to all column ends of the last story as shown in Figure 16. This additional structure enhances the robustness and redundancy of the building, making available more alternate load paths and providing a wider and more effective redistribution. In particular, it is conceived to redistribute part of the load also to the farthest columns from the position of the column removal so as to avoid overloading of the nearest columns.
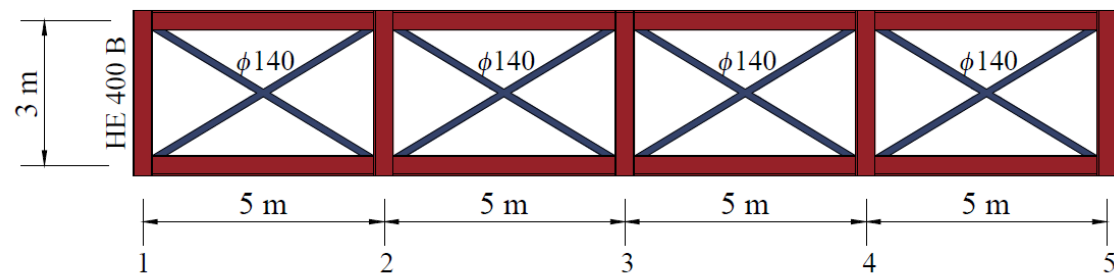

$5 \mathrm{~m}$

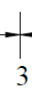

$5 \mathrm{~m}$

Figure 16. 'Roof-truss' system.

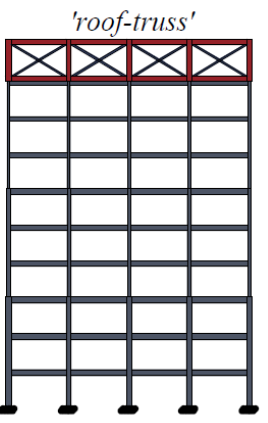

\subsection{Retrofitted case study structure}

The 'roof-truss' designed for the retrofitted structure in Figure 16 is characterized by being $3 \mathrm{~m}$ high, by steel sections for the horizontal and vertical components corresponding to HE $400 \mathrm{M}$ and by circular diagonals with diameter $\phi=$ $140 \mathrm{~mm}$. The steel grade S355 is used with nominal yield strength $f_{y}=355 \mathrm{MPa}$ and Young's modulus $E=210000$ MPa. The OpenSees model of the frame, described in Section 2, has been updated to include the 'roof-truss' system. This is modeled with 'elasticBeamColumn' elements [41] for the horizontal and vertical members of the truss as they are expected to behave elastically. However, the adequacy of this simplification has been checked a posteriori. 


\subsection{Non-linear dynamic analysis and Dynamic Increase Factor (DIF)}

431 Non-linear dynamic analyses of the retrofitted structure were performed considering all internal column loss scenarios

432 (i.e., columns 2, 3 and 4 in Figure 1). The analyses showed that there is no significant difference in terms of load 433 redistribution capacity between these three scenarios and the following part of the paper focuses on the results of the central column removal.

Similarly to what done for the existing structure, the results of the IDA, for different $\lambda$ values, and of the non-linear static analysis in terms of peak node displacement $\delta$ and axial force $N$ in the column adjacent to the removed one are shown in Figure 17 together with the comparison of the response of the existing structure. It can be observed that the 'roof-truss' provides a significant reduction of the peak node displacements $\delta$, while the axial force $N$ reduction is more moderate. This is expected as, despite the presence of the 'roof-truss' allows for a better load redistribution, the columns still have to carry the gravity load. The displacement and load variations are strongly affected by the 'rooftruss' stiffness as discussed in the following Sections. Moreover, it is noteworthy that, being the progressive collapse of the existing structure observed in the form of a brittle mechanism (i.e., column buckling), the retrofit measure needs to be designed to ensure an elastic behavior of the structure as observed in Figure 17. Figure 18 shows the values of the DIFs for both the node displacement $\left(D I F_{\delta}\right)$ and the axial force $\left(D I F_{N}\right)$ calculated according to Eq.s (3). It is worth highlighting that due to the retrofitting, the structure does not experience non-linear deformations for $\lambda$ values lower than 1.00 and hence the DIFs are constant for the whole spectrum of load intensities of interests. In addition, Figure retrofit strategy in reducing the dynamic amplification effects.
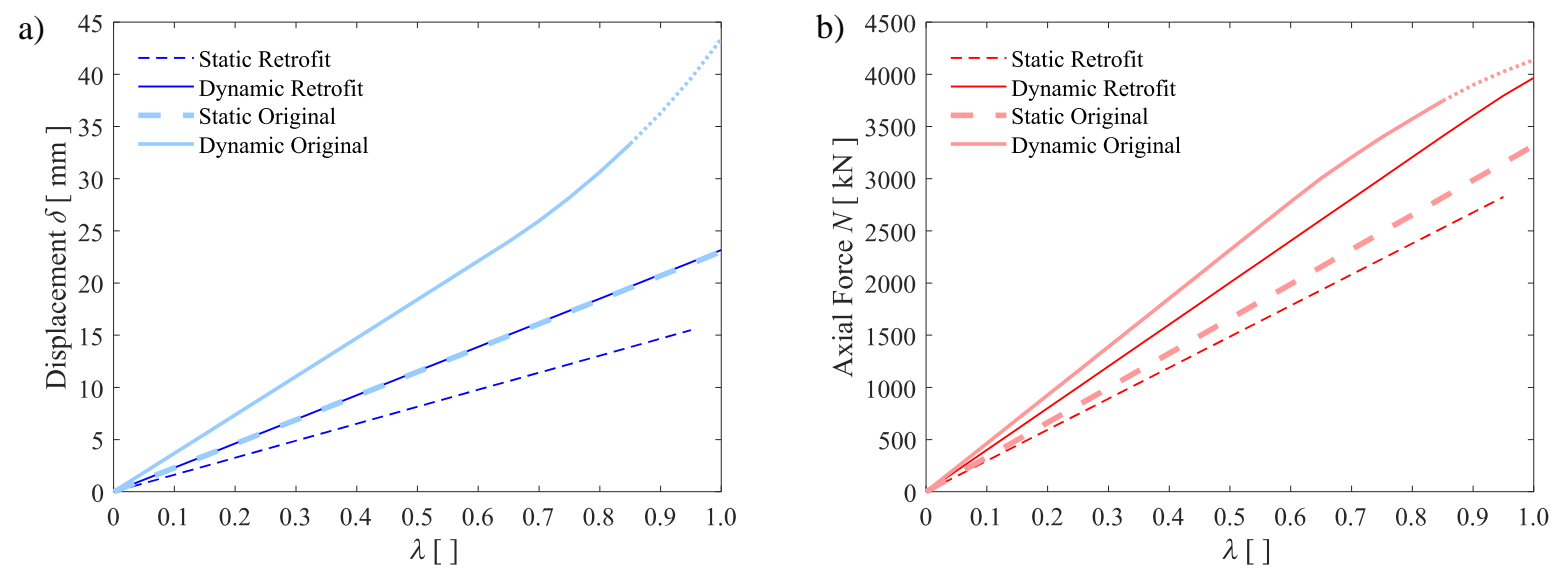

Figure 17. Comparisons of Static and Dynamic response parameters for DIF calculation for: (a) node displacement 


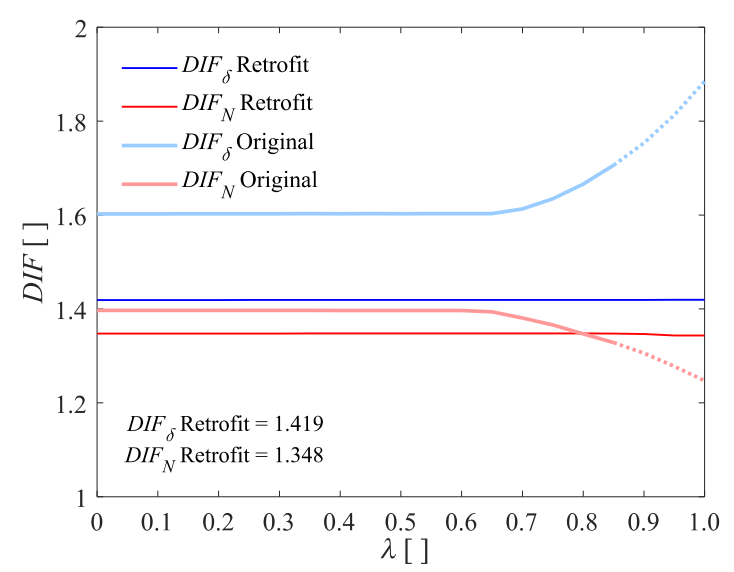

Figure 18. DIF calculation for the existing and retrofitted case study structure.

\subsection{Non-linear static analysis}

Based on the $D I F_{N}$ derived in the previous Section, a $D I F_{N}{ }^{*}$ coefficient equal to 1.496 has been derived to be used in the non-linear static analyses of the retrofitted structure. The results are shown in Figure 19, where it appears how the removal simulation could be completed, and the redistribution achieved was sufficient to achieve the predetermined objectives. The reached lower node displacement $\delta$ demonstrates an improved vertical stiffness provided by the retrofit system. As a result, less load acts on the beams at each story which shows even lower participation in terms of both bending moments and axial forces, that, for the sake of brevity are not reported here. This is due to the vertical stiffness of the retrofit system that activates an alternative load path that consists in adding load in tension to the columns above the removal, that reaches the 'roof-truss' and that is redistributed to further 'safe' columns, avoiding extreme overloading of the adjacent ones as proved from the lower $W R$ and horizontal displacements of column middle nodes shown in Figure 19a and b.

Figure 20 shows the column axial force distribution considering several situations of interest i.e., before and after the column removal of the existing structure and of the retrofitted structure. Due to symmetry conditions, only column lines 1, 2 and 3 are shown in the figure. It can be observed that the beneficial effects of the retrofitting results in a more uniformly distributed axial load in all the columns constituting the frame. The axial forces are reduced in the columns adjacent to the removal (i.e., column lines 2 and 4), while an increase is observed in the further ones (i.e., column lines 1 and 5). However, this retrofit solution enlightened some critical aspects. It can be observed that the introduction of the 'roof-truss' entails higher values of tension in the columns above the removal. As these members were not designed for this load condition, failure could be reached due to yielding of the columns or due to failure of 
the column splice in tension. Thus, attention should be paid to these details when employing this retrofit strategy.

To provide a better understanding of the influence of the 'roof-truss' stiffness, Figure 20 also shows the results obtained with the introduction of an ideal 'infinitely' stiff 'roof-truss' relative to existing structure vertical stiffness. It can be observed that, increasing the 'roof-truss' stiffness, generates a better redistribution of the axial forces in the columns with a higher engagement of the farthest columns (i.e., column lines 1 and 5) and an additional reduction of the axial forces in the columns adjacent to the removal (i.e., column lines 2 and 4). However, despite this beneficial effect, it can be observed that the 'infinitely' stiff 'roof-truss' also generates an increase in the tensile axial force in the column line of the removal at the higher stories.
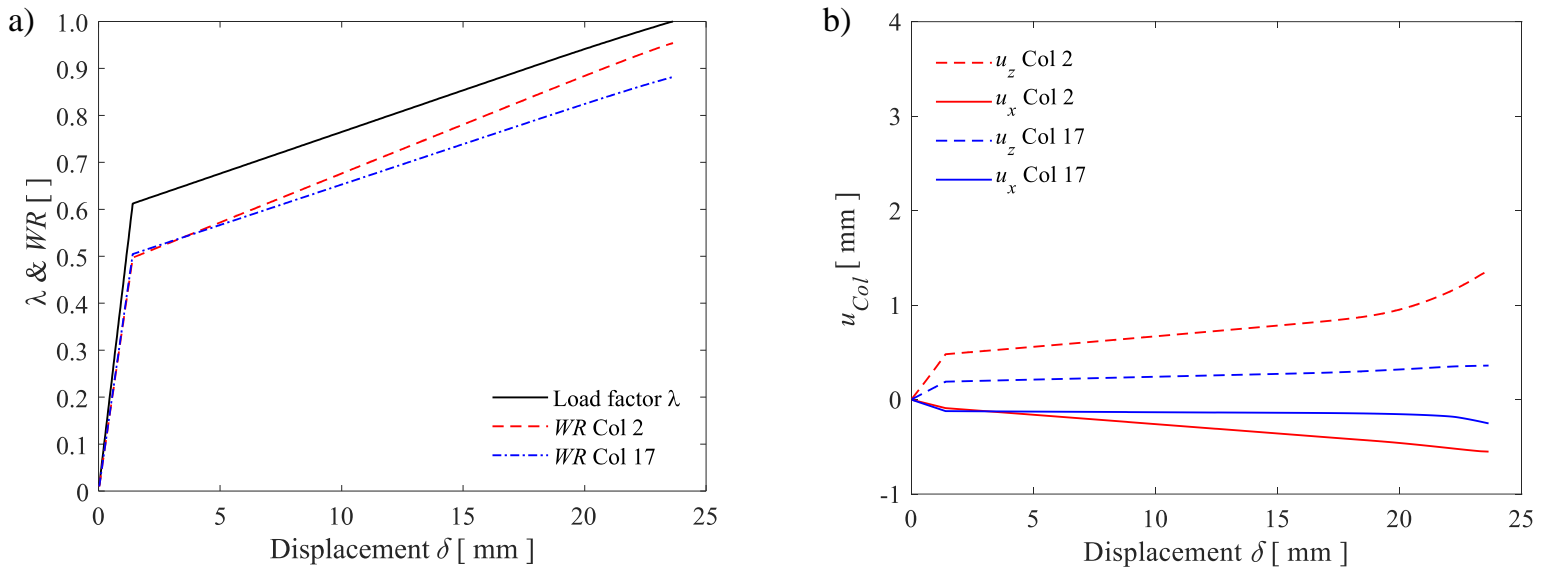

Figure 19. Results of removal analysis of retrofitted structure: (a) load factor $(\lambda)$ and the WR of the most stressed 481 columns; (b) horizontal displacements of columns' middle nodes $\left(u_{\mathrm{Col}}\right)$ of retrofitted structure.

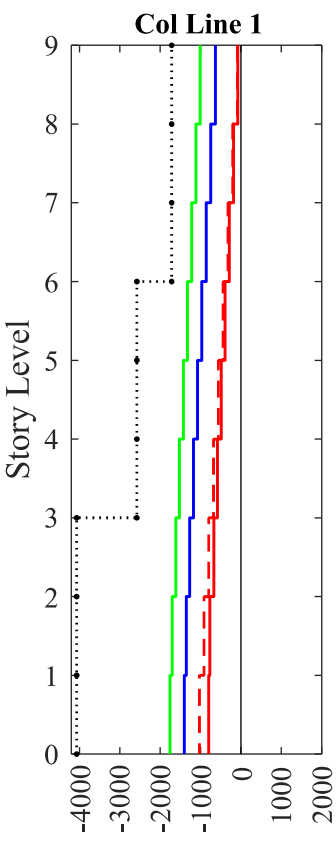

482
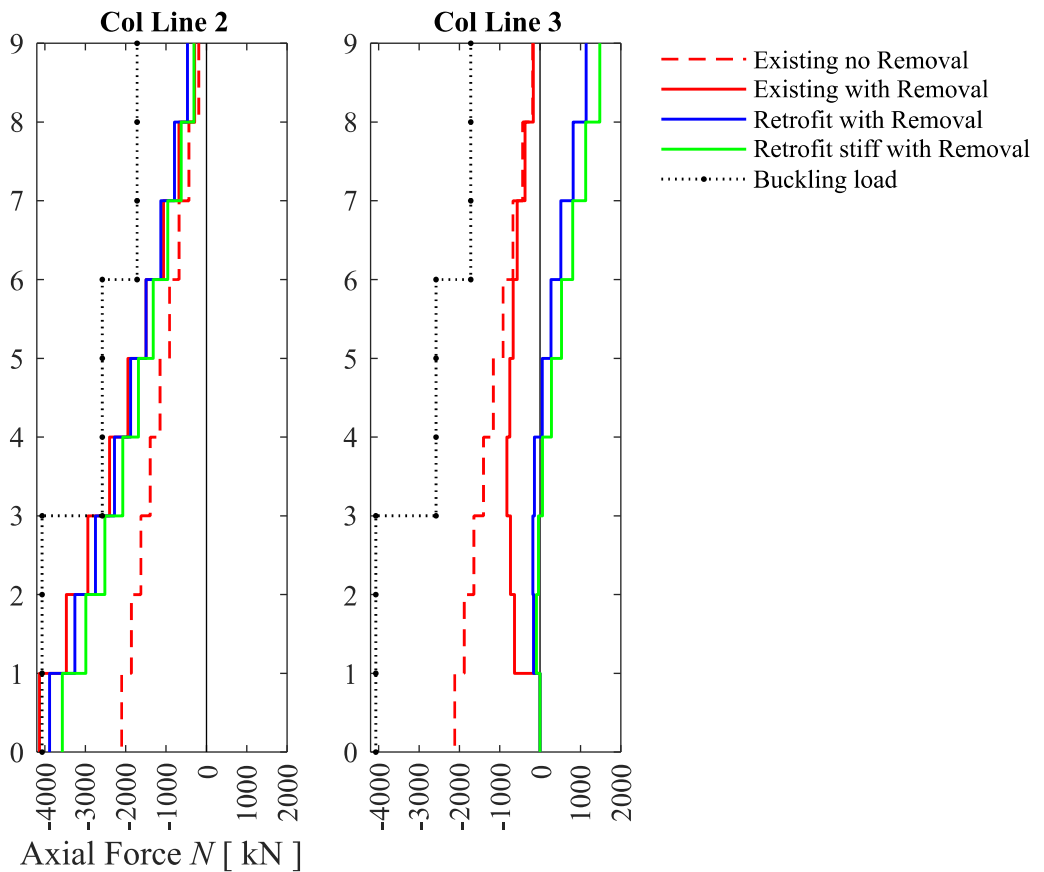
Figure 21 shows the relative participation of the columns of a same story. Figure 21a shows the variation of the $W R$ of the columns at the first story by considering the existing structure and the two retrofit options before and after the column removal. It can be observed that, while, as expected, the retrofit options do not significantly affect the force distribution before the column loss, they allow a better redistribution of the axial forces after column removal, hence avoiding buckling of the remaining columns. Moreover, it can be observed that the 'infinitely' stiff 'roof-truss' allows a better redistribution of the loads. Figure $21 \mathrm{~b}$ shows the same results at the last story. Also in this case the retrofit options do not significantly affect the force distribution before the column loss. However, significant effects are observed after the column removal. In this case, the use of the 'infinitely' stiff 'roof-truss' results in the highest variation of axial forces in the columns and hence in the highest values of the $W R$. Figure $21 \mathrm{~b}$ shows $W R$ for the last story columns that are below 1 . However, additional checks are required for the column splices that could require local interventions. The results show the high influence of the stiffness of the 'roof-truss' and the need for a careful calibration of stiffness and strength of this retrofit option in order to achieve an optimized solution able to reach the design objectives while also limiting the needs for local intervention. Moreover, despite some beneficial effects can be observed by the use of a stiffer 'roof-truss', this could imply large profiles and consequently detailing to joint it with the existing structure could become difficult.

a)

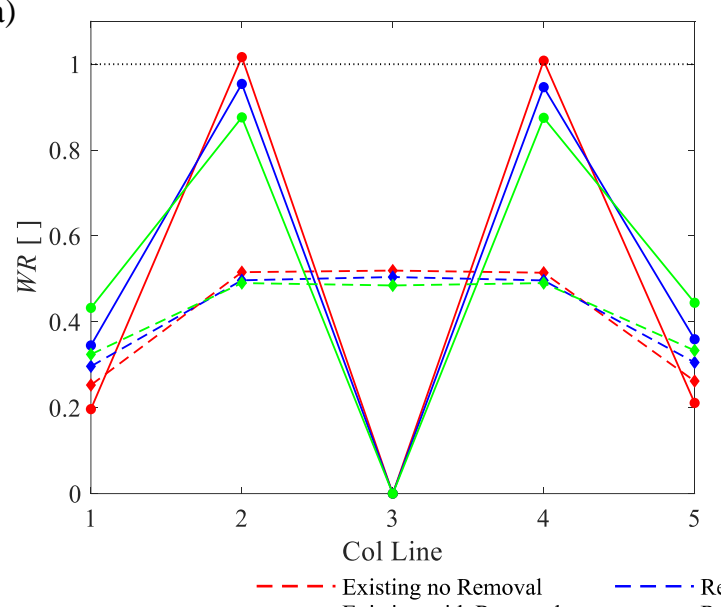

b)

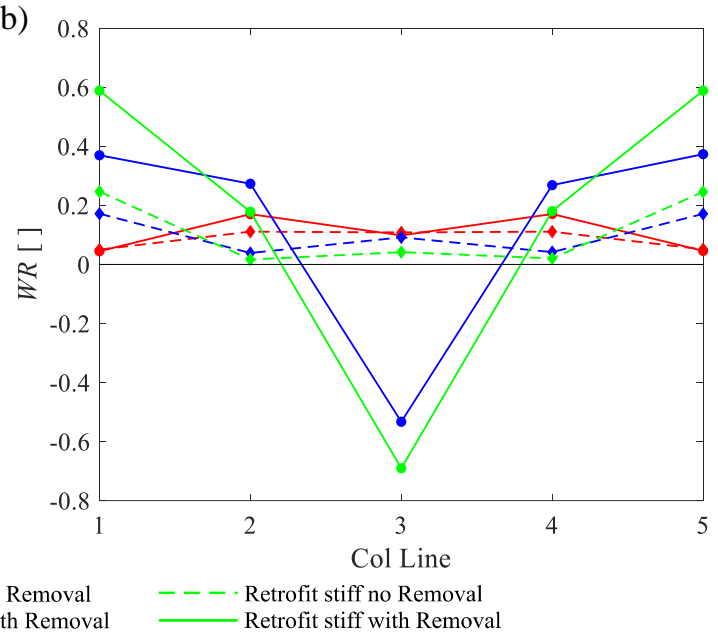

Figure 21. Work ratio (WR) of columns axial force $N$ at: (a) first story; (b) top story.

500 The results show that, for the considered case study, the use of the 'roof-truss' does not allow retrofitting against

501 lateral column removal scenarios, thus highlighting the need for the 'roof-truss' introduction also in the perpendicular direction. 


\section{4 'Roof-truss' stiffness and strength calibration}

505 Figure 22 shows the truss system considered and the variables that control the stiffness and resistance of the 'roof506 truss'. The influence of the three main parameters was investigated: the height $H$ of the 'roof-truss', the area $A_{D}$ of the 507 diagonals and the area $A_{M}$ of the horizontal and vertical elements, respectively. The number and spans of the bay width 508 is the same of the original frame studied and the removal was assumed in the central column. A parametric analysis 509 on these three parameters was performed showing the main trends for the stiffness and resistance of the 'roof-truss' 510 considering the central column loss scenario. The stiffness $K$ has been taken as the force $F$ above the removal divided 511 by the corresponding vertical displacement $\delta$ and the diagonals are assumed to be able to support compressive forces 512 without buckling.

513 Figure 23a shows the variability of force and stiffness with respect to $A_{D}$ and $A_{M}$ by considering the height of the 514 'roof-truss' $H$ equal to $3 \mathrm{~m}$. An increase of $A_{D}$ yields the increase of the 'roof-truss' strength, while $A_{M}$ affects its 515 stiffness without any effect on the final resistance for large displacements. Figure 23b shows, by considering $A_{D}$ equal 516 to $150 \mathrm{~cm}^{2}$, the variability with respect to $H$ and $A_{M}$. With this regard, an initial range of height values can be detected 517 as responsible of a stiffness increase. Beyond a limit value, it starts to decrease, meaning lower effectiveness of the 518 higher truss system.

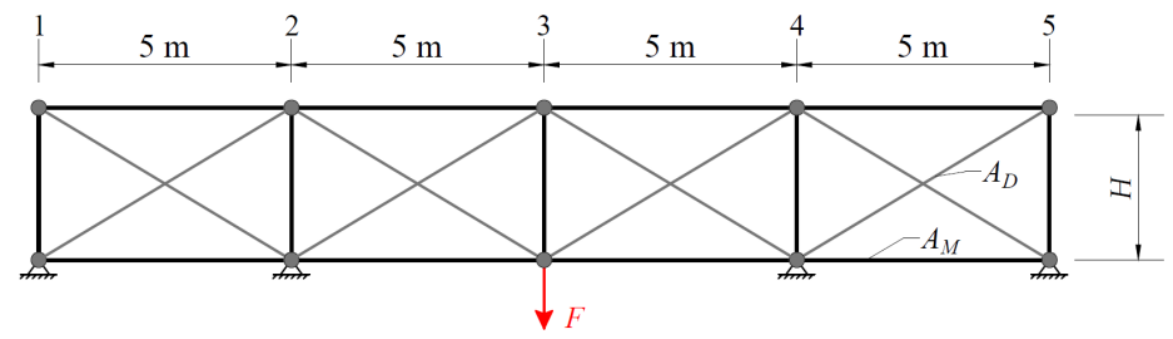

Figure 22. Roof-truss model for a central column removal scenario. 

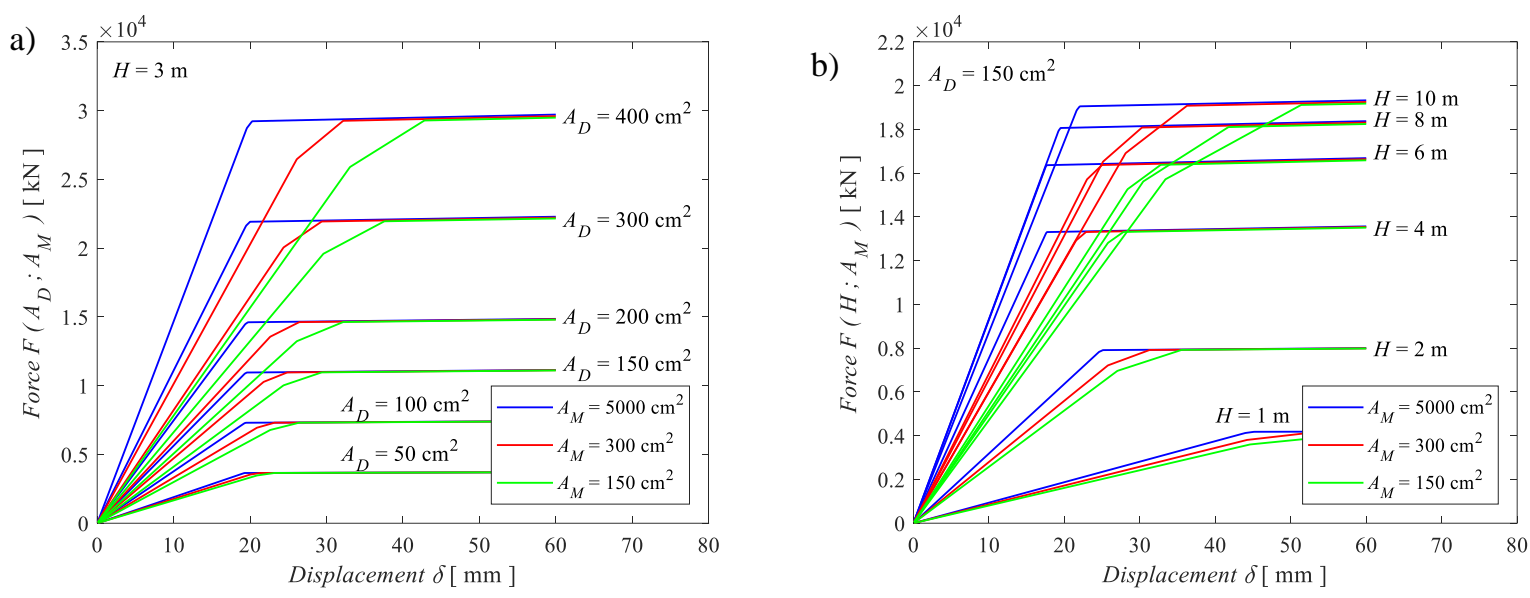

Figure 23. Results of the 'roof-truss' parametric analyses.

522 Analytical formulation for the yielding force $F$ and stiffness $K$ can be easily derived under the assumption of infinitely stiff horizontal and vertical elements as reported in the following Eq. (5) hence providing useful insights for the design and for the strength and stiffness calibration of the 'roof-truss'.

$$
F\left(A_{D}, H\right)=4 A_{D} f_{y} \sin \left(\tan ^{-1} \frac{H}{L}\right) \quad ; \quad K\left(A_{D}, H\right)=\frac{4 A_{D} E}{H}\left[\sin \left(\tan ^{-1} \frac{H}{L}\right)\right]^{3}
$$

\section{CONCLUSIONS}

The present paper investigates the performance and the design of a retrofit solution to increase the robustness of steel load path, was investigated as a retrofit solution. The work investigates the robustness of the structure under the column loss scenario. The numerical simulations allowed the identification of the possible failure modes and alternative load paths together with several considerations related to the Dynamic Increase Factor $(D I F)$. The outcomes show how the proposed retrofit solution allows the definition of effective alternative load paths within the analyzed structure when subjected to column loss scenarios and provide several insights for its design. The following considerations can be drawn:

- The failure mode observed as a consequence of the column loss scenario is related to the buckling of the column adjacent to the column removal. This failure mode is not comprehensively considered in the codes as highlighted by the lack of adequate $D I F$ coefficients for brittle failure modes and additional studies are required in this direction. 
- The introduction of the 'roof-truss' results in two main beneficial effects that allow reaching the design objective: 1) the introduction of the 'roof-truss' allows a more uniform distribution of axial forces in the columns after the column removal; 2) the dynamic amplification effects are less noticeable due to the introduction of the 'rooftruss' i.e., DIF reduction, hence contributing to the reduction of the axial forces in the columns.

- The stiffness of the 'roof-truss' needs to be carefully designed. A very stiff 'roof-truss' may generate a significant increase in axial forces in some columns which may require local intervention, e.g., high tension forces at the high stories of the removed column and need for the strengthening of column splices in tension. A careful design of stiffness and strength of the 'roof-truss' allows reaching the design objectives while reducing the extension of the local retrofit measures required.

- The influence of the two main parameters affecting stiffness and strength of the 'roof-truss', i.e., the high $H$ and the area $A$ of the diagonals of the 'roof-truss' has been investigated by a parametric analysis. The results of the parametric analysis provide insights for the initial sizing of the 'roof-truss' geometric characteristics.

It is worth mentioning that the case study selected represents a 'difficult' situation for the implementation of such retrofit system for progressive collapse, yet it demonstrated the feasibility and the effectiveness of the retrofit strategy. In fact, both the number of stories (i.e., mid- to high-rise building) and the rigid welded beam-to-column connections considered in this study, promote the formation of the column-type failure. The study is limited to a single case study, however, based on the above consideration, the investigated solution can be effectively applied to other case studies, considering different structural configurations (i.e., braced frames, gravity frames), different types of beam-to-column connections, different geometries, and dimensions. The introduction of the 'roof-truss' could be more effective in structures where the failure is related to excessive beam rotations such, e.g., low-rise structures with flush-end plate beam-to-column connection. Additionally, three-dimensional 'roof-truss' retrofit strategies could provide enhanced performances in terms of load redistribution capacity. In fact, a three-dimensional 'roof-truss' would allow a redistribution of the loads among a larger number of columns, would be able to effectively protect side and corner columns, and will provide additional freedom in the design of stiffness and strength of the 'roof-truss'. Future studies are required in this direction.

\section{ACKNOWLEDGEMENTS}

Nicola Tondini would like to acknowledge the support received from the Italian Ministry of Education, University and Research (MIUR) in the frame of the 'Departments of Excellence' (grant L 232/2016). 


\section{REFERENCES}

1. Adam, J. M., Parisi, F., Sagaseta, J., Lu, X. 2018. "Research and practice on progressive collapse and robustness of building structures in the $21^{\text {st }}$ century”. Eng. Struct. 173: 122-149.

2. El-Tawil, S., Li, H., Kunnath, S. 2014. "Computational Simulation of Gravity-Induced Progressive Collapse of Steel-Frame Buildings: Current Trends and Future Research Needs.” J. Struct. Eng., 140 (8): A2513001: 1-12.

3. Randaxhe J., Popa N., Tondini N. 2021 "Probabilistic fire demand model for steel pipe-racks exposed to localised fires.” Eng. Struct. 226: 111310.

4. Tondini N., Thauvoye C., Hanus F., Vassart O. 2019 "Development of an analytical model to predict the radiative heat flux to a vertical element due to a localised fire", Fire Safety J. 105: 227-243.

5. Tondini N. and Franssen J.-M. 2017 “Analysis of experimental hydrocarbon localised fires with and without engulfed steel members.” Fire Safety J. 92: 9-22.

6. Hoffman, N., Kuhlmann, U., Demonceau, J.F., Jaspart, J.P., Baldassino, N., Freddi, F., Zandonini, R. 2015. "Robust impact design of steel and composite building structures: The Alternate Load Path Approach.” In Proc. IABSE Workshop 2015, Safety, Robustness and Condition Assessments of Structures, Helsinki, Finland.

7. Pearson, C., Delatte, N. 2005. "Ronan Point apartment tower collapse and its effect on building codes.” J. Perform. Constr. Fac. 19 (2): 172-177.

8. Sozen, M. A., Thornton, C. H., Corley, W. G., Mlakar, P. F. 1998. "The Oklahoma city bombing: Structure and mechanisms of the Murrah Building." J. Perform. Constr. Fac. 12 (3): 120-136.

9. Bažant, Z. P., Verdure, M. 2007. "Mechanics of progressive collapse: Learning from World Trade Center and building demolitions." J. Eng. Mech. 133 (3): 308-319.

10. Demonceau, J. F., Jaspart, J. P. 2010. "Experimental test simulating a column loss in a composite frame.” $A d v$. Steel Constr. 6 (3): 891-913.

11. Yang, B., Tan, K. H. 2013. "Experimental tests of different types of bolted steel beam column joints under a central-column-removal scenario.” Eng. Struct. 54: 112-30.

12. Liu, C., Tan, K. H., Fung, T. C. 2013. "Dynamic behaviour of web cleat connections subjected to sudden column removal scenario.” J. Constr. Steel Res. 86: 92-106.

13. D'Antimo, M., Latour, M., Rizzano, G., Demonceau, J. F. 2019. "Experimental and numerical assessment of steel beams under impact loadings.” J. Constr. Steel Res. 158: 230-247.

14. Jahromi, H. Z., Izzuddin, B. A., Nethercot, D. A., Donahue, S., Hadjioannou, M., Williamson, E. B., Engelhardt, 
M., Stevens, D., Marchand, K., Waggoner, M. 2012. "Robustness assessment of building structures under explosion." Buildings 2 (4): 497-518.

15. Zandonini, R., Baldassino, N., Freddi, F. 2014. "Robustness of steel-concrete flooring systems. An experimental assessment.” Stahlbau 83 (9): 608-613.

16. Song, B. I., Sezen, H. 2013. "Experimental and analytical progressive collapse assessment of a steel frame building." Eng. Struct. 56: 664-672.

17. Dinu, F., Marginean, I., Dubina, D., Petran, I. 2016. "Experimental testing and numerical analysis of 3D steel frame system under column loss.” Eng. Struct. 113: 59-70.

18. Dinu, F., Marginean, I., Dubina, D. 2017. "Experimental testing and numerical modelling of steel momentframe connections under column loss.” Eng. Struct. 151: 861-878.

19. Li, H., Cai X., Zhang L., Zhang B., Wang W. 2017 "Progressive collapse of steel moment-resisting frame subjected to loss of interior column: Experimental tests”, Eng. Struct., 150:203-220.

20. Johnson, E. S., Meissner, J. E., Fahnestock, L. A. 2016. "Experimental Behavior of a Half-Scale Steel Concrete Composite Floor System Subjected to Column Removal Scenarios.” J. Struct. Eng. 142 (2): 04015133: 1-12.

21. Stathas, N., Karakasis, I., Strepelias, E., Palios, X., Bousias, S., Fardis, M. N. 2019. “Tests and analysis of RC building, with or without masonry infills, for instant column loss.” Eng. Struct. 193: 57-67.

22. Zandonini, R., Baldassino, N., Freddi, F., Roverso, G. 2019. "Steel-concrete composite frames under the column loss scenario: an experimental study.” J. Constr. Steel Res. 162: 105527.

23. Izzuddin, B. A., Vlassis, A. G., Elghazouli, A. Y., Nethercot, D. A. 2007. "Progressive collapse of multi-storey buildings due to sudden column loss - Part I: Simplified assessment framework.” Eng. Struct. 30: 1308-1318.

24. Vlassis, A. G., Izzuddin, B. A., Elghazouli, A. Y., Nethercot, D. A. 2007. "Progressive collapse of multi-storey buildings due to sudden column loss - Part II: Application.” Eng. Struct. 30: 1424-1438.

25. Sadek, F., El-Tawil, S., Lew, H. 2008. "Robustness of composite floor systems with shear connections: modeling, simulation, and evaluation." J. Struct. Eng. 134: 1717-25.

26. Alashker, Y., El-Tawil, S., Sadek, F. 2010. "Progressive collapse resistance of steel-concrete composite floors." J. Struct. Eng. 136: 1187-96.

27. Jahromi, H. Z., Vlassis, A. G., Izzuddin, B. A. 2013. "Modelling approaches for robustness assessment of multistorey steel-composite buildings.” Eng. Struct. 51: 278-294.

28. Khan, S., Saha, S. K., Matsagar, V. A., Hoffmeister, B. 2017. "Fragility of Steel Frame Buildings under Blast 
Load.” J. Perform. Constr. Fac. 31 (4): 04017019.

29. Stephen, D., Lam, D., Forth, J., Ye, J., Tsavdaridis, K. D., 2019. "An evaluation of modelling approaches and column removal time on progressive collapse of building." J. Constr. Steel Res. 153: 243-253.

30. Dimopoulos, C., Freddi, F., Karavasilis, T.L., Vasdravellis, G. 2020. "Progressive collapse of Self-Centering moment resisting frames.” Eng. Struct. 208: 109923.

31. Parisi, F., Scalvenzi, M. 2020. "Progressive collapse assessment of gravity-load designed European RC buildings under multi-column loss scenarios.” Eng. Struct. 209: 110001.

32. Vlassis, A. G., Izzuddin, B. A., Elghazouli, A. Y., Nethercot, D. A. 2006. "Design oriented approach for progressive collapse assessment of steel framed buildings.” Struct. Eng. Int. 16 (2): 129-136.

33. Stevens, D., Crowder, B., Sunshine, D., Marchand, K., Smilowitz, R., Williamson, E., Waggoner, M. 2011. “DoD Research and Criteria for the Design of Buildings to Resist Progressive Collapse.” J. Struct. Eng. 137 (9): 870-880.

34. CEN (European Committee for Standardization). 2006. Eurocode 1: Actions on structures - Part 1-7: General actions - Accidental actions. EN 1991-1-7. Brussels, Belgium.

35. DOD (United States Department of Defense). 2016. Unified Facilities Criteria (UFC) - Design of structures to resist progressive collapse. 4-023-0314. July 2009 - Change 3, 1 November 2016, Arlington, Virginia.

36. GSA (General Services Administration). 2003. Progressive collapse analysis and design guidelines for new federal office buildings and major modernization projects. Washington, DC.

37. Galal, K., El-Sawy, T. 2010. "Effect of retrofit strategies on mitigating progressive collapse of steel frame structures.” J. Constr. Steel Res. 66 (4): 520-531.

38. Liu, J. L. 2010. "Preventing progressive collapse through strengthening beam-to-column connection, part 1: theoretical analysis.” J. Constr. Steel Res. 66 (2): 229-37.

39. Ghorbanzadeh, B., Bregoli, G., Vasdravellis, G., Karavasilis, T. L. 2019. "Pilot experimental and numerical studies on a novel retrofit scheme for steel joints against progressive collapse.” Eng. Struct. 200: 109667.

40. Papavasileiou, G., Pnevmatikos, N. 2018. "Optimized retrofit of steel-concrete composite buildings against progressive collapse using steel cables." In Proc. 16 th European Conference on Earthquake Engineering (ECEE), Thessaloniki, Greece.

41. Mazzoni, S., McKenna, F., Scott, M. H., Fenves, G. L. 2009. "Open system for earthquake engineering simulation user command-language manual, OpenSees Version 2.0.” University of California, Berkeley, CA. 
42. Mirvalad, S. J. 2013. "Robustness and Retrofit Strategies for Seismically-Designed Multistory Steel Frame Buildings Prone to Progressive Collapse." PhD thesis, Concordia University, Montreal, Canada.

43. Ciman, L., Tondini, N., Freddi, F. 2020. “A Retrofitting Methods to Mitigate Progressive Collapse in Steel Structures." In Proc. The $9^{\text {th }}$ European Conference on Steel and Composite Structures (Eurosteel 2020), Sheffield, UK.

44. Mashhadi, J., Saffari, H. 2017. "Effects of Postelastic Stiffness Ratio on Dynamic Increase Factor in Progressive Collapse.” J. Perform. Constr. Facil. 31 (6): 04017107.

45. CEN (European Committee for Standardization). 2002. Eurocode 1: Actions on structures - Part 1-1: General actions - Densities, self-weight, imposed loads for buildings. EN 1991-1-1. Brussels, Belgium.

46. CEN (European Committee for Standardization). 2005. Eurocode 3: Design of steel structures - Part 1-1: General rules and rules for buildings. EN 1993-1-1. Brussels, Belgium.

47. CEN (European Committee for Standardization). 2005. Eurocode 8: Design of structures for earthquake resistance. Part 1: General rules, seismic action and rules for buildings. EN 1998-1. Brussels, Belgium.

48. Gerasimidis, S., Bisbos, C., Baniotopoulos, C. 2012. "Vertical geometric irregularity assessment of steel frames on robustness and disproportionate collapse." J. Constr. Steel Res. 74: 76-89.

49. Gerasimidis, S. 2014. "Analytical assessment of steel frames progressive collapse vulnerability to corner column loss.” J. Constr. Steel Res. 95: 1-9.

50. Gerasimidis, S., Baniotopoulos, C. 2015. "Progressive collapse mitigation of 2D steel moment frames: assessing the effect of different strengthening schemes." Stahlbau 84 (5): 324-331.

51. Lee, C-H., Kim, S., Lee, K. 2009. "Parallel axial-flexural hinge model for non linear dynamic progressive collapse analysis of welded steel moment frames.” J. Struct. Eng. 136 (2): 165-173.

52. Kim, J., An, D. 2009. "Evaluation of progressive collapse potential of steel moment frames considering catenary action." Struct. Des. Tall Spec. 18 (4): 455-465.

53. Castro, J. M., Elghazouli, A. Y., Izzuddin, B. A. 2005. "Modelling of the panel zone in steel and composite moment frames." Eng. Struct. 27: 129-144.

54. Charney, F. A., Downs, W. M. 2004. "Modeling procedures for panel zone deformations in moment resisting frames." In Proc. Conference on Connections in Steel Structures V: Innovative Steel Connections, Amsterdam, the Netherlands. 